\title{
Fair and unfair income inequalities in Europe
}

\author{
Daniele Checchi, University of Milan \\ Vito Peragine, University of Bari \\ Laura Serlenga, University of Bari
}

\begin{abstract}
This paper analyses the extent of income inequality and opportunity inequality in 25 European countries. The present work contributes to understanding the origin of standard income inequality, helping to identify potential institutional setups that are associated to opportunity inequality. We distinguish between ex ante and ex post opportunity inequality. We find that ex ante equality of opportunity exhibits positive correlation with public expenditure in education, whereas ex post equality of opportunity is also positively associated to union presence and to fiscal redistribution.
\end{abstract}

JEL Classification: D31, D63, J62

Keywords: Inequality of opportunity, income inequality. 


\section{Introduction}

In this paper we propose a methodology to measure the degree of inequality of opportunities and to decompose overall income inequality into two components: unfair inequalities, i.e., income inequality due to initial and exogenous circumstances and fair inequalities, i.e., income inequality due to individual effort and responsibility. We then apply this methodology to measure inequalities in 25 European countries and make an attempt to correlate the extent of opportunity inequality to institutional aspects of such countries.

Measuring the degree of inequality of opportunity is interesting per se, if one believes that "levelling the playing field", rather than equalizing the final results, is the objective of a "just society". This position has been put forward in the last decades by philosophers such as Dworkin (1981a,b), Arneson (1989), Cohen (1989) and by economists such as Roemer (1993, 1998) and Fleurbaey $(1995,2008)$. These authors have defended the idea that differences in outcomes due to exogenous circumstances are ethically unacceptable and should be compensated (Compensation Principle); while differences due to effort are to be considered ethically acceptable and do not need any intervention (Reward Principle ${ }^{1}$ ).

In addition to normative reasons, the evidence we propose can have an important instrumental value. First, social attitudes towards redistributive policies may be affected by the knowledge, or the perception, of the origin of income inequalities (Alesina and La Ferrara, 2005): existing surveys show that most people judge income inequalities arising from different levels of effort as less objectionable than those due to exogenous circumstances as race, family origin, etc.. Hence, by showing that a large amount of existing inequalities is due to unequal ex-ante opportunities may increase the support for redistributive policies. Second, opportunity inequality, rather than income inequality, can be strongly related to aggregate economic performance: it has been suggested (Bourguignon et al. 2007 and World Bank, 2006) that the existence of strong and persistent inequalities in the initial opportunities open to individuals can generate true inequality traps that represent severe constraints to future perspectives of growth of an economy, by preventing entire groups from participation into economic and social life ${ }^{2}$. Finally, the analysis of opportunity inequality might help to understand the generation of income inequality and to identify the priorities of public intervention: the knowledge of the factors explaining income inequality can help to identify the more deprived groups in a society, thereby revealing new points of emphasis in social and redistributive policies.

\footnotetext{
${ }^{1}$ We refer here to the utilitarian version of the reward principle. A different "liberal" version could also be formulated (see Fleurbaey 2008).

${ }^{2}$ Indeed, an empirical analysis of the relation between opportunity inequality and growth is an interesting task for future research.
} 
For example, two countries A and B may exhibit the same level of overall income inequality and still being in need of very different public interventions if in one country there is a much larger fraction of inequality attributable to, say, ethnic or gender factors. While in the first case income redistribution, via the tax system, and universal social protection may be the adequate policy measures, in the latter case more tailor-made, categorical interventions could be advisable.

We believe that these considerations are relevant for many European countries and for the debate on social protection and social policies in Europe. Nevertheless, the literature on the measurement of inequality of opportunity, both at the methodological and the empirical level, is still in its infancy. See among others, Bourguignon et al. (2003), Checchi and Peragine (2009), Dardanoni et al. (2006), Ferreira and Gignoux (2008), Lefranc et al. (2008), Moreno-Ternero (2007), Paes de Barros et al. (2009), Peragine (2002, 2004a,b), Peragine and Serlenga (2008), Pistolesi (2009), Villar (2006), World Bank (2006). This literature has developed two main approaches to measuring opportunity inequality, namely the ex-ante and the ex-post approach. According to the ex-ante approach, there is equality of opportunity (EOp) if the set of opportunities is the same for all individuals, regardless of their circumstances. This approach consists of partitioning the population in types formed by individuals endowed with the same circumstances: the income distribution within a circumstance class is interpreted as the opportunity set open to individuals in that class. Hence, in order to measure opportunity inequality, one focuses on the inequality between types. On the other side, according to the ex-post approach, there is EOp if and only if all those who exert the same effort end out with the same outcome. This means that opportunity inequality within this approach is measured as inequality within responsibility classes, i.e. within the set of individuals at the same effort level.

These two approaches express different and sometimes conflicting views on equality of opportunity ${ }^{3}$ and in fact the rankings they generate may be different. However, most of the existing empirical analysis of opportunity inequality have adopted an ex ante approach. In this paper we explore both the ex ante and the ex post approach and we offer some insights on the different results they provide. In the estimation of opportunity inequality we compare parametric models vis a vis with non parametric methods of decomposition. Each method has pros and cons: the non parametric models avoid the arbitrary choice of a specific functional form on the relationship between outcome, circumstances and effort; on the other hand, parametric models allow studying partial effects of circumstances on outcome, other things constant (i.e. they make it easier building and studying counterfac-

\footnotetext{
${ }^{3}$ Fleurbaey and Peragine (2009) study the clash between ex ante and ex post notions of EOp.
} 
tuals).

The empirical application is divided in two parts. First, we provide estimates of income inequality and opportunity inequality in 25 European countries available in the EU-SILC database. Our results show that although the expected ranking among Northern European and Mediterranean countries is generally respected, our measures of inequality of opportunities shed new light on the distributional patterns of European countries. It is possible to identify roughly three groups of countries: $i$ ) formerly centrally planned economies (Poland, Lithuania, Latvia and Estonia, plus Portugal as outlier) that reach higher levels of total inequality, and intermediate levels of opportunity inequality; ii) most of continental Europe exhibit relatively high levels of inequality of opportunity, despite moderate levels of total inequality; iii) the "egalitarian" countries, where both types of inequality obtain the lowest values (Nordic countries plus Slovenia and Slovak Republic).

Our results also highlight the difference between the ex ante and ex post approaches: these approaches do capture different aspects of opportunity inequality and are associated to different sets of institutions, corresponding to pre- and post-labour market entry. Existing data indicate that equality of opportunity, in the ex ante version, is positively correlated with public expenditure in education. Equality of opportunity, when measured ex post, is also positively associated to union presence and to fiscal redistribution.

The paper is organized as follows. Section 2 introduces our methodology for measuring opportunity inequality and decomposing overall income inequality. Section 3 contains our empirical analysis: the data description, the estimating procedure and the discussion of the results. Section 4 concludes with some final remarks and some directions for future research.

\section{Measuring opportunity inequality: a simple model}

Each individual in our society is completely described by a list of traits, which can be partitioned into two different classes: circumstances and effort. The first class includes traits beyond the individual responsibility, represented by a person's set of circumstances c, belonging to a finite set $\Omega=\left\{\mathbf{c}_{1}, \ldots, \mathbf{c}_{n}\right\}$. Circumstances include a vast list of income generating inputs that are out of control of the individual, like gender, age, ethnicity, region of residence or parental background. Various notions of equality of opportunity correspond to different choices of which of these variables are to be regarded as circumstances. ${ }^{4}$ If the only circumstances were gender, which can only take values in the set $\{$ male, female $\}$, and parental education, that only takes values in the set \{graduate parents, non graduate parents\},

\footnotetext{
${ }^{4}$ Geographical differences are an example of circumstances which can either be treated as exogenously given, or under the control of an individual who may choose migration.
} 
then the set $\Omega$ would be the following: $\Omega=(\{$ female, non graduate parents $\}$, $\{$ female, graduate parents $\},\{$ male, non graduate parents $\},\{$ male, graduate parents\}).

The second class includes factors for which the individual is fully responsible and is represented by a scalar variable, effort, $e \in \Theta$. We assume that effort is one-dimensional. It is important to remind that by effort in this paper we mean not only the extent to which a person exerts himself, but all the other background traits of the individual that might affect his success, but that are excluded from the list of circumstances. This amounts to say that any other factors, as native ability, talent, or even luck, are implicitly classified as within the sphere of individual responsibility. This assumption may lead us to overestimate the portion of inequality which is ethically acceptable, and conversely to underestimate equality of opportunity ${ }^{5}$.

Income is generated by a function $g: \Omega \times \Theta \rightarrow \mathbb{R}_{+}$, that assigns individual incomes to combinations of effort and circumstances:

$$
x=g(\mathbf{c}, e)
$$

To save notation, we may also write $x(\mathbf{c}, e)$ and refer to it as both the individual income and the relevant income distribution.

We assume that the function $g$ is monotonically increasing in effort $e$. As for the relationship between circumstances and effort, we believe that the assumption of orthogonality between these two components would be excessively restrictive (Checchi and Peragine 2009): rather, we consider the case in which preferences are partly determined by circumstances and hence we distinguish between a direct effect of circumstances on outcomes and an indirect effect via the choice of effort.

We now consider two different partitions of the total population. First, for $\mathbf{c}_{i} \in \Omega$, we call type $i$ the set of individuals whose set of circumstances is $\mathbf{c}_{i}$. The type income distribution represents the set of outcome levels which can be achieved - by exerting different degrees of effort - starting from the same circumstance $\mathbf{c}_{i}$. That is to say, the type distribution is a representation of the opportunity set - expressed in terms of outcomes open to any individual endowed with circumstances $\mathbf{c}_{i}$.

The second partition is based on the effort variable: for $e \in \Theta$, we call tranche $e$ the set of individuals whose effort is $e$. However, as we are considering the case of non observability of effort, we need to deduce the degree of effort from some observable behavior. Following Roemer (1993, 1998) we say that all individuals at the $p^{\text {th }}$ quantile of the effort distribution in their types, have tried equally hard. Given the monotonicity of the income function, this will correspond to the quantile in the income distribution of the type.

\footnotetext{
${ }^{5}$ On the effect of partial observability of the circumstances on the estimates of opportunity inequality see Luongo and Peragine (2009).
} 
Thus, we define the tranche $p$ in a population as the subset of individuals whose effort is at the $p^{\text {th }}$ rank of their respective type distributions. The two partitions suggest two different approaches to measure opportunity inequality.

The first approach focuses on ex post inequalities in classes of individuals with identical effort. Consequently, it looks at the tranches distributions.

The ex post approach. There is EOp if all those who exerted the same degree of effort have the same outcome. Inequality of opportunity decreases if outcome inequality decreases among the individuals at the same degree of effort.

Thus, the ex post approach ${ }^{6}$ emphasizes inequalities within effort groups: it is therefore an expression of the principle of compensation. On the other hand, differences between the tranches are interpreted as due to individual effort, and are not considered as unfair.

In contrast, the second approach focuses on the types distributions and is based on the following definition of equality of opportunity.

The ex ante approach. There is EOp if the set of opportunities is the same, regardless of the circumstances. Inequality of opportunity decreases if inequality between individual opportunity sets decreases.

Thus, the ex ante approach ${ }^{7}$ puts special emphasis on the differences in the outcome prospects for classes of individuals with identical circumstances. Accordingly, it focuses on inequality between types, and is instead neutral with respect to inequality within types. By stating the irrelevance of the effort based inequalities within each types, the ex ante approach is an expression of a reward-focused approach to equality of opportunity (see Fleurbaey 2008, ch. 9).

Both approaches appear as relevant and plausible, and it is difficult to give priority to one or another. Therefore, we now develop each of them in turn, and for each of them we provide a measure of opportunity inequality.

\subsection{The ex-post approach}

In the ex post approach opportunity inequality is given by inequality within tranches. To capture such inequality we may construct an hypothetical standardized distribution obtained after the following transformation:

$$
x(\mathbf{c}, e) \rightarrow \frac{x(\mathbf{c}, e)}{x(\overline{\mathbf{c}}, e)} x(\overline{\mathbf{c}}, \bar{e})
$$

\footnotetext{
${ }^{6}$ This is the approach proposed by Roemer $(1993,1998)$ and defended by Fleurbaey (2008).

${ }^{7}$ This approach has been proposed, in different frameworks, by Van de Gaer (1993), Kranich (1996), Peragine (2004a).
} 
where $x(\overline{\mathbf{c}}, e)$ is the artificial distribution obtained by using a constant reference value of circumstances $\overline{\mathbf{c}}$, and $x(\overline{\mathbf{c}}, \bar{e})$ is obtained by using reference values of both circumstances and effort.

Note that for every scale invariant inequality measure $I$ :

$$
I\left(\frac{x(\mathbf{c}, e)}{x(\overline{\mathbf{c}}, e)} x(\overline{\mathbf{c}}, \bar{e})\right)=I\left(\frac{x(\mathbf{c}, e)}{x(\overline{\mathbf{c}}, e)}\right) .
$$

Hence, in the ex post approach inequality of opportunity is given by a (scale invariant) inequality index $I$ applied to the artificial distribution $\frac{x(\mathbf{c}, e)}{x(\overline{\mathbf{c}}, e)}:$

$$
O I^{e x-p o s t}=I\left(\frac{x(\mathbf{c}, e)}{x(\overline{\mathbf{c}}, e)}\right)
$$

or, in relative terms:

$$
O I_{\text {relative }}^{\text {ex-post }}=\frac{I\left(\frac{x(\mathbf{c}, e)}{x(\overline{\mathbf{c}}, e)}\right)}{I(x(\mathbf{c}, e))} .
$$

What is the meaning of the reference value $x(\overline{\mathbf{c}}, e)$ ? This depends on the specific measurement approach one decides to adopt ${ }^{8}$ : in a non parametric approach $x(\overline{\mathbf{c}}, e)$ may be interpreted as the average income of a given tranche identified by $e$ (call it $\left.\mu_{e}\right)$, and $x(\overline{\mathbf{c}}, \bar{e})$ as the grand mean of the overall distribution (call it $\mu$ ). Then for any path independent measure of inequality ${ }^{9}$ (Foster and Shneyrov, 2000) we have:

$$
I(x(\mathbf{c}, e))=I\left(\frac{x(\mathbf{c}, e)}{\mu_{e}}\right)+I\left(\mu_{e}\right)
$$

The distribution $x(\mathbf{c}, e)$ is the original income vector; $\mu_{e}$ is a hypothetical smoothed distribution in which each person's income is replaced with the mean income of the tranche she belongs to. This smoothing process removes all inequality within the tranches, hence $I\left(\mu_{e}\right)$ captures the inequality only due to individual responsibility; $\frac{x(\mathbf{c}, e)}{\mu_{e}}$ is a standardized distribution obtained by proportionally scaling each tranche distribution until it has the same mean as the overall distribution. Standardization suppresses betweentranche inequality while leaving within tranche inequality unaltered. Hence

\footnotetext{
${ }^{8}$ Different interpretations are possible: for instance, in a normative approach, $x(\overline{\mathbf{c}}, e)$ could be represented by the equally distributed equivalent income of a given tranche identified by $e$.

${ }^{9}$ In particular, we need to use the mean logarithmic deviation (MLD), which is the only index which has a path-independent decomposition using the arithmetic mean as the representative income. For a distribution $X=\left(x_{1}, \ldots, x_{N}\right)$ with mean $\mu_{X}$ the $M L D$ is defined as:

$$
M L D(X)=\frac{1}{N} \sum_{i=1}^{N} \ln \frac{\mu_{X}}{x_{i}}
$$
}


$I\left(\frac{x(\mathbf{c}, e)}{\mu_{e}}\right)$ fully captures the income inequality due to circumstances only, i.e. the inequality of opportunity.

Hence the decomposition above can be interpreted as:

total inequality $=$ within tranches inequality + between tranches inequality total inequality $=$ opportunity inequality + effort inequality

Thus, we have a measure of opportunity inequality and a decomposition of overall inequality into an ethically acceptable and an ethically offensive part.

In a parametric analysis this procedure corresponds to estimate, for each tranche $(p)$, the following equation

$$
\ln x_{i}=\beta_{p} \mathbf{c}_{i}+\varepsilon_{i},
$$

where $\mathbf{c}_{i}$ is the all set of circumstances, and obtaining a counterfactual distribution of income as $\hat{x}_{p}=\exp \left(\hat{\beta}_{p} \overline{\mathbf{c}}_{p}\right)$, where $\overline{\mathbf{c}}_{p}$ is the average value of characteristics in each tranche. Inequality of opportunity can be therefore calculated parametrically by $I\left(\frac{x_{i}}{\hat{x}_{p}}\right)$.

Both the parametric and non parametric measures proposed so far implicitly assume no correlation between circumstances and effort. Hence they are able to measure only the direct effect of circumstances on outcomes.

As discussed above, a more plausible option is that effort is somehow related to circumstances and therefore there exists a distribution of effort, $F_{\varepsilon_{i}}^{t}$, for each type, $\varepsilon_{i}^{t}$. In order to take into account the possible correlation, following Björklund et al. (2010), we control for the difference in distributions of effort by considering heterogeneous variances $\sigma_{t}^{2}=\operatorname{Var}\left[\varepsilon_{i}^{t} \mid \mathbf{c}_{i}^{t}\right]$, and rewrite (1) as

$$
\ln x_{i}=\beta \mathbf{c}_{i}+\varepsilon_{i}^{t}-\underbrace{\frac{\varepsilon_{i}^{t}}{k \sigma_{t}}}_{u_{i}}+\underbrace{\frac{\varepsilon_{i}^{t}}{k \sigma_{t}}}_{u_{i}},
$$

where $k=\frac{1}{\sigma}, \sigma$ is the overall variance and $u_{i}$ is a residual with variance $\sigma^{2}$ across all types. Hence total inequality is now decomposed in three parts: the first term captures the pure effect of circumstances, the component $\tilde{\varepsilon}_{i}^{t}=$ $\left(\varepsilon_{i}^{t}-u_{i}\right)$ is a residual term which measures individual effort correlated to circumstances, whose variance varies across type, whereas the component $u_{i}$ is a residual which proxies for "pure" individual effort - not influenced by circumstances - whose variance does not vary across type. If effort is correlated to circumstances, the residual $u_{i}$ is a better proxy for effort; hence in what follows we use such a measure of effort to partition the population into tranche and derive a direct measure of ex-post inequality. ${ }^{10}$

\footnotetext{
${ }^{10}$ As noted in Björklund et al. (2010), in order to implement this procedure we should
} 


\subsection{The ex-ante approach}

In the ex ante approach opportunity inequality is given by inequality between types. To capture such inequality we may construct an hypothetical smoothed distribution obtained after the following transformation:

$$
x(\mathbf{c}, e) \rightarrow x(\mathbf{c}, \bar{e})
$$

where $x(\mathbf{c}, \bar{e})$ is the artificial distribution obtained by using a constant reference value of effort $\bar{e}$.

Hence, in the ex ante approach inequality of opportunity is given by a (scale invariant) inequality index $I$ applied to the distribution $x\left(\mathbf{c}_{i}, \bar{e}\right)$ :

$$
O I^{e x-a n t e}=I(x(\mathbf{c}, \bar{e}))
$$

or, in relative terms:

$$
O I_{\text {relative }}^{\text {ex-ante }}=\frac{I(x(\mathbf{c}, \bar{e}))}{I(x(\mathbf{c}, e))} .
$$

The meaning of $x\left(\mathbf{c}_{i}, \bar{e}\right)$ depends again on the specific measurement approach one decides to adopt.

In a non parametric descriptive approach $x(\mathbf{c}, \bar{e})$ can be represented by the average income of a given type identified by $\mathbf{c}\left(\right.$ call it $\left.\mu_{c}\right)$. Then for any path independent measure of inequality (Foster and Shneyrov, 2000) we have that

$$
I(x(\mathbf{c}, e))=I\left(\frac{x(\mathbf{c}, e)}{\mu_{c}}\right)+I\left(\mu_{c}\right) .
$$

The interpretation is as follows: by measuring the inequality in the artificial vector $\mu_{c}$, obtained by replacing each income with its type mean income, we capture only and fully the between-types inequality, which, in turn, reflects the opportunity inequality. On the other hand, by rescaling all type distributions until all types have the same mean income, hence obtaining the distribution $\frac{x(\mathbf{c}, e)}{\mu_{c}}$, we are left with an income vector in which the only inequality present is the within-types inequality, to be interpreted as inequality due to individual responsibility. Hence the decomposition above can be interpreted as:

total inequality $=$ within types inequality + between types inequality total inequality $=$ effort inequality + opportunity inequality

first estimate the $\beta$ coefficients and then, based on OLS residual, the type-specific variances $\sigma_{t}$. However, in the case where the types have few observations this will lead to small $\sigma_{t}$ and large $u_{i}$. We therefore once again follow Björklund et al. (2010) and regress the estimated variances on background characteristics, and use fitted values from that regression as basis for $\frac{\varepsilon_{i}^{t}}{k \sigma_{t}}$. 
Thus, again, we have a measure of opportunity inequality and a decomposition of overall inequality into an ethically acceptable and an ethically offensive part. As for the ex post approach, inequality of opportunity by the ex ante approach can also be computed parametrically. Also in this case we consider the possible interaction between effort and circustances and estimate (2) for the whole population such that

$$
\ln x_{i}=\beta \mathbf{c}_{i}+\tilde{\varepsilon}_{i}^{t}+u_{i}
$$

Hence, we derive the following counterfactual distributions $\hat{x}_{i}=\exp \left(\hat{\beta} \mathbf{c}_{i}\right)$ and $\exp \left(\tilde{\varepsilon}_{i}^{t}\right)$. According to the ex ante approach, inequality consists of three parts: one due to circumstances, $I\left(\hat{x}_{i}\right)$, that can be computed in a parametric and non parametric way, the direct ex-ante; one due to effort correlated to circumstances, $I\left(\exp \left(\tilde{\varepsilon}_{i}^{t}\right)\right)$, the ex ante type variation due to effort or indirect ex-ante, which can only be identified parametrically, and a residual due to pure effort. ${ }^{11}$

In the following empirical analysis we will compare our estimates ${ }^{12}$ of $O I^{\text {ex-post }}$ (parametric and non parametric) and $O I^{\text {ex-ante }}$ (parametric and non parametric) and use them for an analysis of the relationship between the extent of opportunity inequality and some relevant policy and institutional variables.

\section{The empirical analysis: income inequality and opportunity inequality in Europe}

\subsection{Data description}

We use data from the 2005 wave of the European Survey on Income and Living Conditions (EUSILC) which is annually conducted by the national Central Statistics Offices (CSOs) in order to obtain information on the income and living conditions of different household types. The survey contains information on a large number of individual and household characteristics as well as specific information on poverty and social exclusion. Representative random samples of households throughout a large number of European countries are approached to provide the required information. We consider 25 countries in our analysis, namely Austria (AT), Belgium (BE), Cyprus (CY), Czech Republic (CZ), Germany (DE), Denmark (DK), Estonia (EE), Spain (ES), Finland (FI), France (FR), Greece (GR), Hungary (HU), Ireland (IE), Italy (IT), Lithuania (LT), Luxembourg (LU), Latvia (LV), the

\footnotetext{
${ }^{11}$ Ferreira and Guignoux (2008).adopt an ex ante approach similar to the one we use. However, they implicitly assume orthogonality between effort and circumstances and therefore do not capture the indirect effect of circumstances.

${ }^{12}$ Notice that when using linear models parametric and non parametric measures give exactly the same results. However, the parametric methods allows to easily provide standard errors for our measure via bootstrapping.
} 
Netherlands (NL), Norway (NO), Poland (PL), Portugal (PT), Sweden (SE), Slovenia (SI), Slovakia (SK) and the United Kingdom (UK). ${ }^{13}$

Differently from other sources of data EUSILC provides a common data source with comparable individual and household level micro-data on income and living conditions in the EU countries, allowing for significant improvements in the comparability of country-specific measures. EUSILC is expected to become the EU reference source for comparative statistics on income distribution and social exclusion at European level. Indeed, our study has been made possible by the inclusion in the 2005 EUSILC survey of a specific data module providing data for attributes of each respondent's parents during her childhood period when aged 14-16. This additional module reports information on family composition, number of siblings, the educational attainment, occupational as well as the labour market activity status of respondent's mother and father and the presence of financial problems in household. In what follows parental education is measured by the highest educational attainment in the parent couple. Individuals are therefore divided in three groups: group 1 refers to individuals having both parents with no education; 2 corresponds to individuals who have at least one parent completing primary or secondary (lower or upper) school degree, while group 3 corresponds to individuals who have at least one of the parents with post-secondary or tertiary degree. Parental occupation is also divided in three categories: category 1 corresponds to individuals having both parents employed in elementary occupations (such as plant and machine operator and assembler - groups 8000 and 9000 in the ISCO88 classification); category 2 refers to individuals who have at least one parent employed in semi-skilled occupations (occupied as service worker, shop and market sales worker, skilled agricultural and fishery worker or as craft and related trades workers - groups from 5000 to 7000 in the ISCO88 classification); finally, category 3 refers to individuals who have at least one of the parents working in top-rank occupations (like legislator, senior official, manager, professional, technician, associate professional or clerk - groups from 1000 to 4000 in the ISCO88 classification). In the empirical analysis we also consider some additional individual characteristics as circumstances. This set comprehends gender, nationality (distinguishing those who declare the country of birth being the same of the country of residence) and geographical location (distinguishing people living in densely populated area form others). Hence, in total we have 72 types. Finally, we partition our sample in ten tranches although results are proved to be generally consistent when considering a different number of tranches.

We restrict the sample to individuals working full-time or part-time, unemployed and those fulfilling domestic tasks and care responsibilities aged

\footnotetext{
${ }^{13}$ The original EUSILC file contains information also on Iceland. However, coding of educational attainment in this case contains errors.
} 
between 30 and $60 .{ }^{14}$ Our outcome variable is post-tax individual earnings; this variable is already available for 18 out of 25 countries under analysis, whereas for the remaining ones we imputed net income from gross income using information available on tax rates in $2004 .{ }^{15}$ Being aware of the fact that welfare indicators estimated from micro-data can be very sensitive to the presence of extreme incomes (Cowell and Victoria-Feser, 1996a, 1996b, 2002) we censored the countries' income distributions by dropping the very extreme values. ${ }^{16}$ Tables 5 and 6 show summary statistics of both individual and parental characteristics.

\subsection{Income and opportunity inequality rankings in Europe}

In this section we aim to provide a ranking of European countries with respect to EOp using both the ex ante and the ex post approach. Starting with the estimates of overall income inequalities, we notice that the ranking based on Gini index from our data is quite consistent with the ranking provided by OECD and Eurostat (see Table 1 and Figure 1). ${ }^{17}$ In particular our evidence shows that Poland, Latvia, Lithuania, Portugal and Estonia obtain the highest values in all data sources. They are followed by the UK, Ireland and Mediterranean countries like Greece, Italy and Spain whereas Nordic countries like Denmark, Finland, Norway and Sweden close the ranking with low values of both Gini and MLD (see also Figure 2). Notice that both here and in the sequel, Slovenia tends to behave like a Nordic country.

Turning to the measurement of inequality of opportunity, our attention is confined to the MLD which is the only index that allows for a perfect decomposition of total income inequality in effort inequality and opportunity inequality; this index still exhibits a country ranking which is not very dissimilar from the one offered by the Gini index (see again Figure 2). As a first insight we notice that inequality of opportunity generally accounts for a substantial share of income inequality in the EU countries under analysis

\footnotetext{
${ }^{14}$ We exclude pupils, students, those in an unpaid work experience, those in retirement or in early retirement, permanently disabled or/and unfit to work, those in compulsory military community or service and other inactive person. However, since the mean logarithmic deviation is computed over positive incomes only, in what follows we are implicitly excluding all individuals with zero incomes. Further results and statistics on the issue are available upon request form the authors.

${ }^{15}$ Tables $7,8,9,10,11$ and 12 in the Appendix show the progressive tax rate used for the conversion. As for Slovakia we used a flat tax rate of $19 \%$ (source: http://www.finance.gov.sk/). Since we do not have information about tax deduction, it is likely that we are obviously overestimating income inequality in net incomes for these countries. However, in the sequel, all these countries (but Netherlands) are grouped as most egalitarian countries.

${ }^{16}$ Van Kerm (2007) discusses how ordinal comparisons of countries are found to be robust to variants of data adjustment procedures such as trimming and winsorizing.

${ }^{17}$ Spearman rank correlation between EUSILC Gini and the ones calculated by OECD and Eurostat are 0.93 and 0.9, respectively.
} 
(see Table (2)). Due to the lack of sufficient information on parental occupation (Sweden and United Kingdom) and degree of urbanization (Netherlands and Slovenia), we have left out these variables while defining circumstances. According to the ex ante approach inequality of opportunity explains from the $2,5 \%$ to the $30 \%$ of income inequality whereas considering the ex post definition we obtain much larger values, from the $16 \%$ to the $45 \%$. As mentioned in the previous section, given the partial observability of circumstances, those values can only be considered as lower bound estimates.

Table (3) shows the ranking obtained by absolute measures of type and tranche approach, respectively. As expected the ex post values are higher than the ex ante ones. Interestingly enough, the ex ante and the ex post measures, although highly correlated, show different rankings of the countries under analysis. This evidence fulfils the theoretical expectations about the different roles played by these two concepts, thus confirming the importance of measuring EOp using both the ex ante and the ex post definitions. Going from the ex ante to the ex post approach we find significant rankreversals, with Germany yielding the largest upward shift, whereas Czech Republic, Estonia, Norway and Portugal worsening their position, achieving lower EOp (see Figure 3). Tables 2 and 3 show also the decomposition of overall inequality of opportunity into a direct term and an indirect term: the latter term, which is intended to capture the effect of circumstances on the choice of effort, account for a portion between $10 \%$ and $25 \%$ of overall opportunity inequality.

What is the meaning to be attributed to these different rankings? By construction, the ex ante approach is focused on the inequality between social types, therefore is less sensitive to inter-individuals inequalities within the same social type. Hence countries which show high level of ex ante opportunity inequality are characterized by bigger distances between social groups. On the other hand, the ex post measures are able to capture in a finer way the individual income gaps due to circumstances. Therefore one could expect the ex ante figures to be less correlated than the ex post figures to overall income inequality: this is in fact confirmed by the data (see Figures 4 and 5). ${ }^{18}$

If we look at Figure 4, we clearly notice three distinct patterns. Most of formerly centrally planned economies ( Hungary, Poland, Lithuania, Latvia and Estonia, plus Portugal as outlier) reach higher levels of total inequality, for given level of EOp. Conversely, most of continental Europe (Chez Republic as an outlier) exhibits relatively higher levels of EOp, despite moderate levels of total inequality. A third group of countries can be detected in the south-west region of the graph, where both types of inequality obtain the lowest values (in addition to Nordic countries - Norway, Sweden, Den-

\footnotetext{
${ }^{18}$ The correlation coefficient between ex ante inequality and total inequality is 0.61 , while the corresponding correlation with the ex post measure is 0.81 .
} 
mark and Finland - we could count Slovenia and Slovak Republic). Results remain consistent even when we consider ex post EOp in Figure 5.

A more consistent grouping can be obtained by applying cluster analysis to the relevant variables (total inequality, ex ante inequality of opportunity and ex post inequality of opportunity), using average-linkage cluster analysis. The corresponding dendrogram shown in Figure 6 indicates that data can be partitioned into two big groups. Starting from the left-hand side we find most of the continental Europe (Austria, Ireland, Netherlands, Cyprus, Germany, Greece, Italy, Spain and United Kingdom, Czech Republic and Hungary as outliers- among them average total inequality 0.20 , ex post opportunity inequality 0.07 , ex ante opportunity inequality 0.03 ) and most of the formerly planned economies (Estonia, Latvia, Lithuania, Poland and Portugal as outlier - in this case the group average are 0.24 (total inequality), 0.07 ( ex post opportunity inequality) and 0.03 (ex ante opportunity inequality)). These countries can be labeled "high income inequality - low equality of opportunities". We then find and intermediate group (France, Luxembourg and Belgium - average inequality measures 0.15, 0.05 and 0.03 respectively), which share low income inequality combined with an intermediate level of EOp. Finally, on the right hand side we find the group of "low income inequality - high equality of opportunities" countries (Slovenia, Sweden, Denmark, Norway, Finland, Slovak Republic - among this group the average total inequality 0.11 , ex post opportunity inequality is 0.03 and ex ante opportunity inequality is 0.01 ).

While recent access to free market may have contributed to the rise in total inequality, it is interesting to notice that not all formerly planned economies correspond to the case of low EOp. Even within continental Europe, we observe differences among countries that are usually grouped together (like France which typically goes with Germany - see Hall and Soskice 2001).

\subsection{Accounting for opportunity inequality: descriptive evi- dence}

In this section we analyze the potential association between institutional characteristics and opportunity inequality. We are perfectly aware that we cannot go beyond suggested correlations, given the limited number of cases in this cross-country analysis. Nevertheless some theoretical expectation can be confronted with the data. For example, we expect the ex ante measure of EOp to be mostly correlated with institutional features of the educational system, because acquired education shape the earning capability of individuals. On the contrary, fiscal redistribution and labour market variables, which are more related to overall income differentials among individuals, are expected to be more correlated to ex post EOp.

Institutional measures are themselves problematic, for they are mostly 
derived from categorical variable that describe procedures (presence/absence of a provision, alternatives available, stages to be accomplished). However we may (partially) account for the role of institutions by resorting to proxy variables, obtained from observed behavior of people acting under a given institution. To provide an example, we know that for historical/cultural/institutional reasons, countries differ in childcare availability. Counting the number of available kindergartens would be a possible candidate for this institutional feature, but data are difficult to collect on a comparable cross-country basis. Resorting to the fraction of children attending kindergarten constitutes a reasonable alternative, which is much simpler to be collected from international/national statistical offices. As with most of institutional measures, this variable is potentially endogenous, since we ignore whether children do not attend kindergartens because they are not available, because their mother prefer housewifery and/or because most of the population still live in enlarged families (where grandparents take care of nursing). Nevertheless, the literature suggests that early schooling may contribute to reducing the role of parental background in competence formation (for example Heckman et al, 2002, and Cunha and Heckman, 2007). As a consequence, other things constant we expect that countries where children attend kindergarten more are also characterised by greater EOp, since income differences by types (ex-ante EOp) should be lower. In the same vein, we know that the stratification of the educational system may reinforce the impact of parents' education, since low educated parents may prevents their kids from aspiring to more academic oriented careers (see for example Hanushek and Wößmann, 2006, and Brunello and Checchi, 2007). The quality of education may also play a role, since it may compensate the disadvantage of students coming from poor environment. Unfortunately, data on school quality are not easily available (unless one is ready to consider students achievements as a proxy for "revealed" quality). More modestly, we have considered economic resources publicly invested in the educational system as proxies for quality of education.

The apparent correlation between our measure of EOp and educational variables is evident in Figures 7 and 8. We do expect that EOp being reinforced by kindergarten attendance ${ }^{19}$ and by comprehensive secondary school systems ${ }^{20}$, because both designs reduces the impact of parental education.

\footnotetext{
${ }^{19}$ Source: OECD online database (http://www.oecd.org/education/database). Data are referred to 2002, and are obtained from Brunello and Checchi (2007). The enrolment in pre-primary schooling of 4-year-old children made available from Eurostat with reference to 2005 was discarded because it was reporting values at $100 \%$ for some countries, contradicting the figures contained in Education at a glance from OECD.

${ }^{20}$ Data from Eurostat 2005 (http://epp.eurostat.ec.europa.eu/portal/page/portal/

statistics/search_database). This indicator provides information on the percentage of boys and girls in upper secondary education who are enrolled in the vocational stream. It is indicative in the importance of initial vocational education and training in a country, taking into account also the gender dimension.
} 
Figure 7 shows that this is true for both dimensions. However, when both variables are taken into account, this weak association tends to vanish (as it can be grasped looking at the first two columns of 4). When considering educational resources (Figure 8), we find that better quality education (i.e. less student per teacher - we were forced to use primary education, as it was the only variable which was non missing ${ }^{21}$ - and/or more expenditure in education over $\mathrm{GDP}^{22}$ ) is associated to greater EOp, both ex ante and ex post EOp. The positive correlation between public expenditure in education and EOp is also statistically significant in multivariate regression (see columns 3-4 of 4$)$.

When we move to labour market institutions, we expect that wage compressing institutions may reduce within-group variance in earnings, thus affecting ex post EOp more than ex ante one. Here data availability, especially for new entrants in the EU, is scarce. We consider two indirect measures of the degree of institutionalisation: the presence of union (proxied by union membership over dependent employment ${ }^{23}$ ) and the degree of employment protection, computed by $\mathrm{OECD}^{24}$. In accordance with the literature, we expected that when the labour market is heavily regulated, wages are less related to individual features, since unions press for job-related pay scales (Visser and Checchi, 2009). In addition, employment protection reduces labour turnover, reducing individual income variability (and therefore aggregate wage inequality). Both measures have been proved to reduce total income inequality in the aggregate (Checchi and García Peñalosa, 2008). Figure 9 shows that in bivariate correlation this is true for union presence, but not for employment protection. When considering multivariate OLS regressions (see columns 5-6 of 4), we find support to our expectation: union presence is positively correlated to EOp, while employment protection is statistically insignificant; moreover, the effect is stronger with respect to ex post EOp than with the ex ante one.

Eventually, we have considered the role of welfare provisions. In general we do not have apriori theoretical expectation on their correlation with EOp, since taxes and subsidies aim to contain income inequality (through taxa-

\footnotetext{
${ }^{21}$ Also from Eurostat 2005. The pupil-teacher ratio is calculated by dividing the number of full-time equivalent pupils by the number of full-time equivalent teachers teaching at ISCED level 1. Only teachers in service (including special education teachers) are taken into account.

${ }^{22}$ Also from Eurostat 2005. This indicator is defined as total public expenditure on education, expressed as a percentage of GDP. Generally, the public sector funds education either by bearing directly the current and capital expenses of educational institutions or by supporting students and their families with scholarships and public loans as well as by transferring public subsidies for educational activities to private firms or non-profit organisations. Both types of transactions together are reported as total public expenditure on education.

${ }^{23}$ Data were kindly made available by Jelle Visser (University of Amsterdam).

${ }^{24} \mathrm{It}$ is the index of overall Employment Protection Legislation (version 2), referred to 2003 (OECD 2004).
} 
tion) and to provide income insurance against unforeseeable events (through subsidies), but in no case they include compensatory measures which attenuate the impact of circumstances. However, as long as fiscal redistribution sustains low incomes (that may be correlated to disadvantaged conditions), we could find some positive correlation with EOp. We have selected two proxies for the welfare state, which are shown in Figure 10. In the left panel we have computed the ratio between the Gini index computed over gross incomes and the Gini index computed over disposable incomes: the larger is the ratio, the stronger is the redistributive role of the state. ${ }^{25}$ We observe a negative correlation with inequality of opportunities, which does not occur when we consider social expenditure in the bottom panels of Figure 10 (at last for the ex ante measure). ${ }^{26}$ When we consider multivariate OLS regressions (see columns 7-8 of 4), once more we find stronger association of fiscal redistribution with ex post EOp than with ex ante EOp, while social expenditure remains statistically insignificant.

\section{Concluding remarks}

In this paper we have presented alternative approaches to measuring inequality of opportunities. We have shown both ex-ante and ex-post approaches, both parametrically and not. We have then applied these methods to European countries, providing rankings based on countries similarities. We have shown that standard income inequality and inequality of opportunities do not necessarily offer the same type of rankings (especially when comparing formerly non market economies with coordinated market economies, like Nordic ones). We then speculate about which is the most favorable institutional environment with respect to maximising EOp. Our results suggest that ex ante equality of opportunity is enhanced by educational institutions that promote lower impact of family backgrounds onto educational attainments (like pre-primary education and higher public expenditure in education). Conversely ex post equality of opportunity is positively correlated to union presence in the labour market and to fiscal redistribution.

\footnotetext{
${ }^{25}$ Data are from the OECD database (http://stats.oecd.org/Index.aspx?DataSetCode= INEQUALITY) and are referred to mid-2000.

${ }^{26}$ From Eurostat 2005: Expenditure on social protection contains: social benefits (transfers, in cash or in kind, to households and individuals to relieve them of the burden of a defined set of risks or needs); administration costs (costs charged to the scheme for its management and administration); other expenditure (miscellaneous expenditure by social protection schemes).
} 
Table 1: Different measures od income inequality

\begin{tabular}{lcccc}
\hline \hline country & OECD Gini & EUROSTAT Gini & EUSILC Gini & EUSILC Mld \\
\hline AT & 0.27 & 0.26 & 0.275 & 0.180 \\
BE & 0.27 & 0.28 & 0.266 & 0.145 \\
CY & & & 0.290 & 0.170 \\
CZ & 0.27 & 0.26 & 0.280 & 0.176 \\
DE & 0.30 & 0.26 & 0.290 & 0.191 \\
DK & 0.23 & 0.24 & 0.217 & 0.083 \\
EE & & & 0.344 & 0.243 \\
ES & 0.32 & 0.32 & 0.314 & 0.216 \\
FI & 0.27 & 0.26 & 0.271 & 0.136 \\
FR & 0.28 & 0.28 & 0.285 & 0.163 \\
GR & 0.32 & 0.33 & 0.316 & 0.200 \\
HU & 0.29 & 0.28 & 0.310 & 0.208 \\
IE & 0.33 & 0.32 & 0.296 & 0.188 \\
IT & 0.35 & 0.33 & 0.309 & 0.196 \\
LT & & & 0.356 & 0.228 \\
LU & 0.26 & 0.26 & 0.276 & 0.148 \\
LV & & & 0.357 & 0.229 \\
NL & 0.27 & 0.27 & 0.270 & 0.192 \\
NO & 0.28 & 0.28 & 0.262 & 0.130 \\
PL & 0.37 & 0.36 & 0.364 & 0.271 \\
PT & 0.38 & 0.38 & 0.354 & 0.247 \\
SE & 0.23 & 0.23 & 0.231 & 0.106 \\
SI & & & 0.239 & 0.104 \\
SK & 0.27 & 0.26 & 0.278 & 0.132 \\
UK & 0.34 & 0.34 & 0.319 & 0.204 \\
\hline
\end{tabular}

Notes: EUSILC Gini and MLD are given by authors' calculations; OECD Gini on working age population and Eurostat Gini are taken from http://stats.oecd.org and OECD (2008). 
Table 2: Inequality of opportunity as a percentage of total inequality

\begin{tabular}{lcccc}
\hline \hline & direct ex ante & indirect ex ante & direct ex post & indirect ex post \\
\hline AT & 0.215 & 0.020 & 0.387 & 0.024 \\
BE & 0.171 & 0.042 & 0.405 & 0.006 \\
CY & 0.300 & 0.053 & 0.453 & 0.006 \\
CZ & 0.108 & 0.022 & 0.381 & 0.011 \\
DE & 0.182 & 0.028 & 0.315 & 0.018 \\
DK & 0.142 & 0.007 & 0.269 & 0.005 \\
EE & 0.107 & 0.030 & 0.324 & 0.017 \\
ES & 0.196 & 0.053 & 0.345 & 0.004 \\
FI & 0.097 & 0.003 & 0.212 & 0.013 \\
FR & 0.127 & 0.015 & 0.285 & 0.011 \\
GR & 0.168 & 0.039 & 0.308 & 0.001 \\
HU & 0.101 & 0.015 & 0.303 & 0.014 \\
IE & 0.223 & 0.047 & 0.441 & 0.045 \\
IT & 0.141 & 0.024 & 0.324 & 0.008 \\
LT & 0.094 & 0.005 & 0.246 & 0.006 \\
LU & 0.235 & 0.039 & 0.401 & 0.004 \\
LV & 0.122 & 0.004 & 0.269 & 0.019 \\
NL & 0.190 & 0.112 & 0.394 & 0.004 \\
NO & 0.025 & 0.005 & 0.344 & 0.008 \\
PL & 0.091 & 0.012 & 0.225 & 0.010 \\
PT & 0.121 & 0.010 & 0.350 & 0.005 \\
SE & 0.111 & 0.011 & 0.241 & 0.000 \\
SI & 0.045 & 0.007 & 0.158 & 0.000 \\
SK & 0.133 & 0.013 & 0.292 & 0.022 \\
UK & 0.205 & 0.038 & 0.406 & 0.058 \\
\hline
\end{tabular}

Notes: Notes: Column 1 reports the amount of the MLD in relative terms due to circumstances; column 2 shows the MLD in relative terms due to type variation of effort; column 3 shows the MLD in relative terms calculated by the tranche approach whereas column 4 reports the ex post type variation of effort. 
Table 3: Inequality of opportunity in absolute term

\begin{tabular}{|c|c|c|c|c|}
\hline & direct exante & indirect ex ante & direct expost & indirect expost \\
\hline \multirow[t]{2}{*}{ AT } & 0.039 & 0.004 & 0.07 & 0.004 \\
\hline & $(0.0005)$ & $(0.0002)$ & $(0.0022)$ & $(0.0002)$ \\
\hline \multirow[t]{2}{*}{$\mathrm{BE}$} & 0.025 & 0.006 & 0.059 & 0.0009 \\
\hline & $(0.0004)$ & $(0.0005)$ & $(0.0028)$ & $(0.0003)$ \\
\hline \multirow[t]{2}{*}{$\mathrm{CY}$} & 0.051 & 0.009 & 0.077 & 0.001 \\
\hline & $(0.001)$ & $(0.0013)$ & $(0.0024)$ & $(0.0002)$ \\
\hline \multirow[t]{2}{*}{$\mathrm{CZ}$} & 0.019 & 0.004 & 0.067 & 0.002 \\
\hline & $(0.0006)$ & $(0.0004)$ & $(0.0043)$ & $(0.0004)$ \\
\hline \multirow[t]{2}{*}{$\mathrm{DE}$} & 0.035 & 0.005 & 0.06 & 0.003 \\
\hline & $(0.0002)$ & $(0.0002)$ & $(0.0012)$ & $(0.0001)$ \\
\hline \multirow[t]{2}{*}{ DK } & 0.012 & 0.0006 & 0.022 & 0.0004 \\
\hline & $(0.0002)$ & $(0.0001)$ & $(0.0008)$ & $(0.0001)$ \\
\hline \multirow[t]{2}{*}{$\mathrm{EE}$} & 0.026 & 0.007 & 0.079 & 0.004 \\
\hline & $(0.0006)$ & $(0.0008)$ & $(0.004)$ & $(0.0004)$ \\
\hline \multirow[t]{2}{*}{$\mathrm{ES}$} & 0.042 & 0.011 & 0.074 & 0.0008 \\
\hline & $(0.001)$ & $(0.001)$ & $(0.002)$ & $(0.0002)$ \\
\hline \multirow[t]{2}{*}{ FI } & 0.013 & 0.0005 & 0.029 & 0.002 \\
\hline & $(0.0003)$ & $(0.00003)$ & $(0.0019)$ & $(0.0002)$ \\
\hline \multirow[t]{2}{*}{ FR } & 0.021 & 0.002 & 0.047 & 0.002 \\
\hline & $(0.0003)$ & $(0.0001)$ & $(0.0014)$ & $(0.0001)$ \\
\hline \multirow[t]{2}{*}{ GR } & 0.034 & 0.008 & 0.062 & 0.0001 \\
\hline & $(0.0007)$ & $(0.0005)$ & $(0.0024)$ & $(0.0002)$ \\
\hline \multirow[t]{2}{*}{$\mathrm{HU}$} & 0.021 & 0.003 & 0.063 & 0.003 \\
\hline & $(0.0007)$ & $(0.0004)$ & $(0.0038)$ & $(0.0004)$ \\
\hline \multirow[t]{2}{*}{ IE } & 0.042 & 0.009 & 0.083 & 0.008 \\
\hline & $(0.0007)$ & $(0.0011)$ & $(0.0039)$ & $(0.0004)$ \\
\hline \multirow[t]{2}{*}{ IT } & 0.028 & 0.005 & 0.063 & 0.002 \\
\hline & $(0.0002)$ & $(0.0002)$ & $(0.0017)$ & $(0.0002)$ \\
\hline \multirow[t]{2}{*}{$\mathrm{LT}$} & 0.021 & 0.001 & 0.056 & 0.001 \\
\hline & $(0.0005)$ & $(0.0001)$ & $(0.004)$ & $(0.0004)$ \\
\hline \multirow[t]{2}{*}{$\mathrm{LU}$} & 0.035 & 0.006 & 0.059 & 0.001 \\
\hline & $(0.0009)$ & $(0.0003)$ & $(0.0021)$ & $(0.0002)$ \\
\hline \multirow[t]{2}{*}{ LV } & 0.028 & 0.001 & 0.061 & 0.004 \\
\hline & $(0.0008)$ & $(0.0001)$ & $(0.0029)$ & $(0.0003)$ \\
\hline \multirow[t]{2}{*}{ NL } & 0.036 & 0.021 & 0.076 & 0.001 \\
\hline & $(0.0004)$ & $(0.0019)$ & $(0.0035)$ & $(0.0003)$ \\
\hline \multirow[t]{2}{*}{$\mathrm{NO}$} & 0.003 & 0.0007 & 0.045 & 0.001 \\
\hline & $(0.00007)$ & $(0.00005)$ & $(0.0017)$ & $(0.0002)$ \\
\hline \multirow[t]{2}{*}{ PL } & 0.025 & 0.0033 & 0.061 & 0.0026 \\
\hline & $(0.0004)$ & $(0.0001)$ & $(0.0017)$ & $(0.0002)$ \\
\hline \multirow[t]{2}{*}{$\mathrm{PT}$} & 0.03 & 0.002 & 0.087 & 0.001 \\
\hline & $(0.0008)$ & $(0.0002)$ & $(0.0058)$ & $(0.0005)$ \\
\hline $\mathrm{SE}$ & 0.012 & 0.001 & 0.026 & 0.000002 \\
\hline & $(0.0002)$ & $(0.0001)$ & $(0.0012)$ & $(0.0001)$ \\
\hline SI & 0.005 & 0.0007 & 0.016 & 0.00004 \\
\hline & $(0.0002)$ & $(0.0001)$ & $(0.0008)$ & $(0.00008)$ \\
\hline SK & 0.018 & 0.002 & 0.038 & 0.003 \\
\hline & $(0.0004)$ & $(0.0001)$ & $(0.0038)$ & $(0.0003)$ \\
\hline UK & 0.042 & $0.008 \quad 20$ & 0.083 & 0.012 \\
\hline & $(0.0008)$ & $(0.0009)^{20}$ & $(0.0049)$ & $(0.0004)$ \\
\hline
\end{tabular}

Notes: Column 1 reports the amount of the MLD in absolute terms due to circumstances; column 2 shows the MLD in absolute terms due to type variation of effort; column 3 shows the MLD in absolute terms calculated by the tranche approach whereas column 4 reports the ex post type variation of effort. Bootstrapped standard errors in parentheses. 
Table 4: Estimated correlation between institutional measures and Inequality of opportunities (absolute measures)

\begin{tabular}{|c|c|c|c|c|c|c|c|c|}
\hline & $\begin{array}{r}1 \\
\text { ex ante }\end{array}$ & $\begin{array}{r}2 \\
\text { ex post }\end{array}$ & $\begin{array}{r}3 \\
\text { ex ante }\end{array}$ & $\begin{array}{r}4 \\
\text { ex post }\end{array}$ & $\begin{array}{r}5 \\
\text { ex ante }\end{array}$ & $\begin{array}{r}6 \\
\text { ex post }\end{array}$ & $\begin{array}{r}7 \\
\text { ex ante }\end{array}$ & $\begin{array}{r}8 \\
\text { ex post }\end{array}$ \\
\hline enrolment in preprimary & -0.0113 & -0.0304 & & & & & & \\
\hline over primary (OECD 2002) & {$[-0.69]$} & {$[-1.27]$} & & & & & & \\
\hline vocational programmes (Eurostat 2005) & $\begin{array}{r}-0.0001 \\
{[-0.71]}\end{array}$ & $\begin{array}{r}-0.0002 \\
{[-1.02]}\end{array}$ & & & & & & \\
\hline expenditure in education/gdp & & & $-0.0052 * *$ & $-0.0102 * *$ & & & & \\
\hline (Eurostat 2005) & & & {$[-3.40]$} & {$[-3.35]$} & & & & \\
\hline pupil/teacher ratio in & & & 0.0003 & -0.0001 & & & & \\
\hline primary school (Eurostat 2005) & & & {$[0.38]$} & {$[-0.05]$} & & & & \\
\hline union density rate $(2005)$ & & & & & $\begin{array}{r}-0.0003^{* *} \\
{[-3.63]}\end{array}$ & $\begin{array}{r}-0.0007^{* *} \\
{[-4.75]}\end{array}$ & & \\
\hline OECD employment protection 1 & & & & & -0.0041 & -0.0062 & & \\
\hline egislation version II (2003) & & & & & {$[-0.99]$} & {$[-0.91]$} & & \\
\hline gini before/after tax and & & & & & & & $-0.0345^{*}$ & $-0.0803^{* *}$ \\
\hline transfer (OECD mid 2000) & & & & & & & {$[-2.50]$} & {$[-3.87]$} \\
\hline expenditure in social & & & & & & & 0.0003 & -0.0002 \\
\hline protection/gdp (Eurostat 2005) & & & & & & & {$[0.80]$} & {$[-0.24]$} \\
\hline Observations & 20 & 20 & 23 & 23 & 18 & 18 & 17 & 17 \\
\hline $\mathrm{R}$-squared & 0.05 & 0.11 & 0.27 & 0.28 & 0.38 & 0.57 & 0.22 & 0.54 \\
\hline Log likelihood & 61.88 & 52.67 & 76.03 & 61.61 & 59.2 & 53.64 & 53.96 & 50.07 \\
\hline
\end{tabular}

Robust t statistics in brackets - constant included - Columns 1-2 exclude Cyprus, Estonia, Latvia, Lithuania and Slovenia. Columns 3-4 exclude Cyprus and Norway; Columns 5-6 exclude Estonia, Cyprus, Latvia, Lithuania, Luxembourg, Slovak Republic and Slovenia. Columns 7-8 exclude Finland, France, Greece, Hungary,Latvia, Lithuania and Slovenia. $* *$ significant at $1 \%{ }^{*}$ significant at $5 \%$. 
Figure 1 - Income inequality according to different data source (OECD and EUSILC)

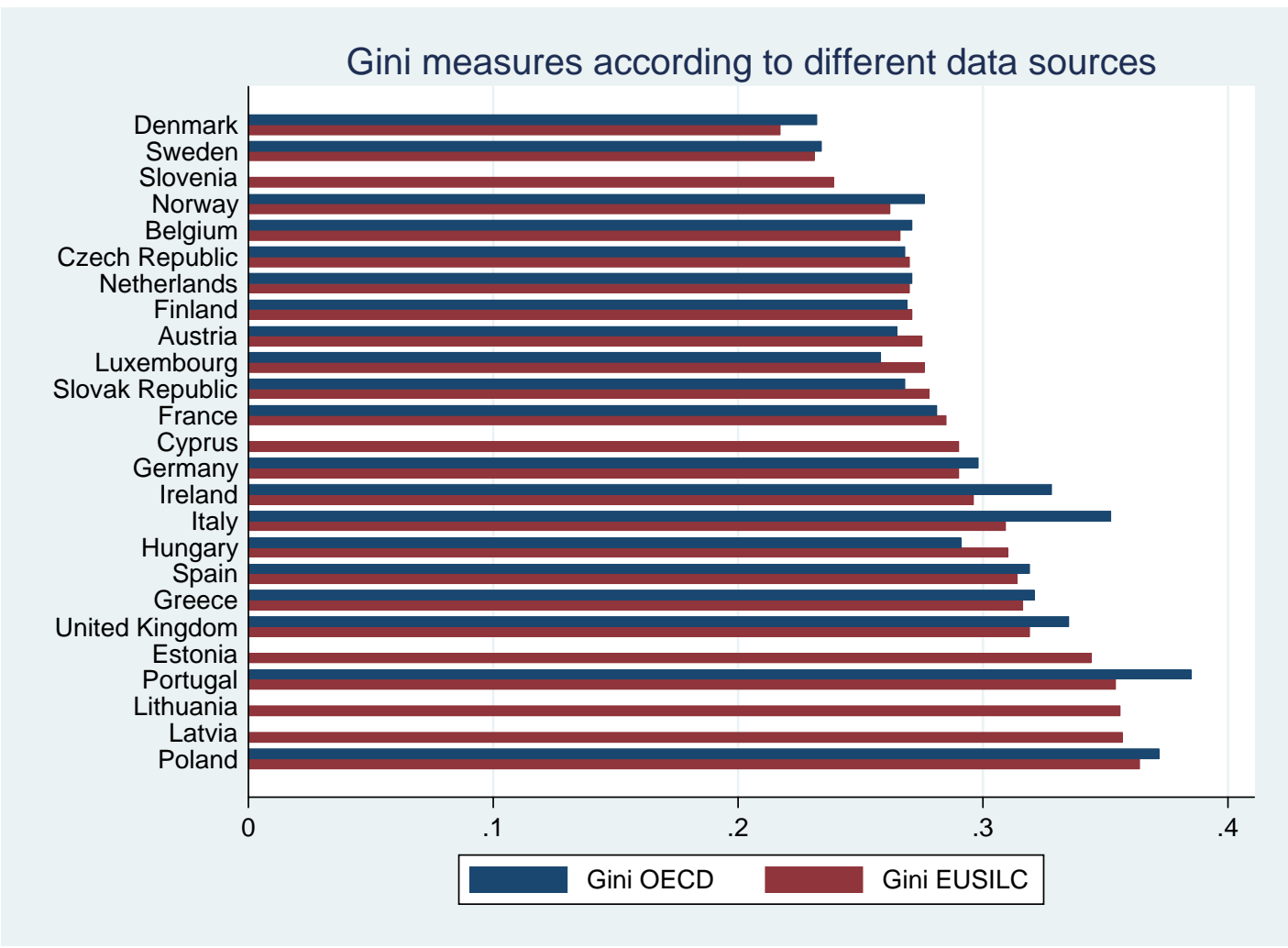

Sources: authors's calculations and http://stats.oecd.org 
Figure 2 - Income inequality according to different indicators (Gini and Mld) - EUSILC 2005

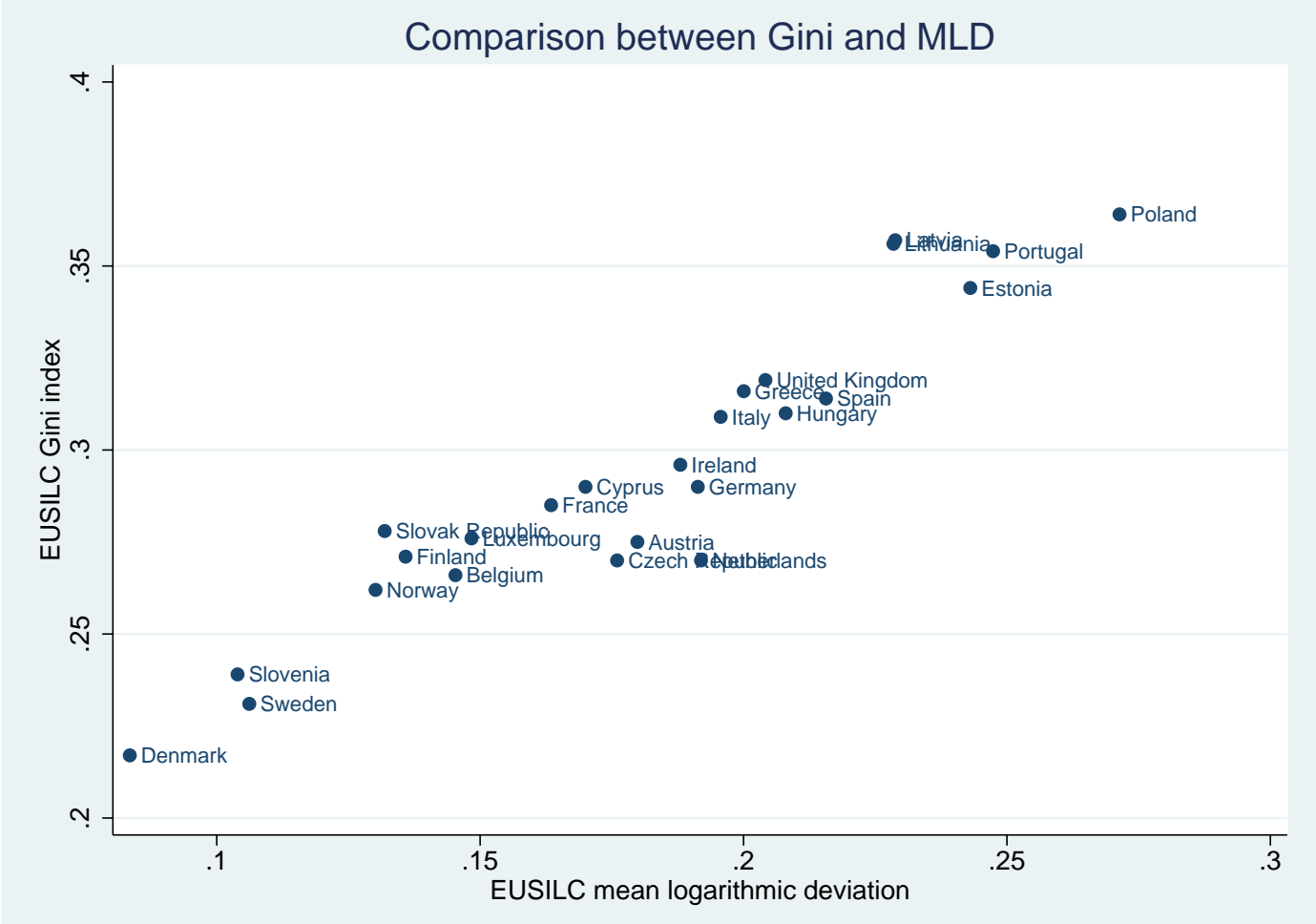

Sources: authors's calculations 
Figure 3 - Absolute opportunity inequality: ex ante and ex post - EUSILC 2005
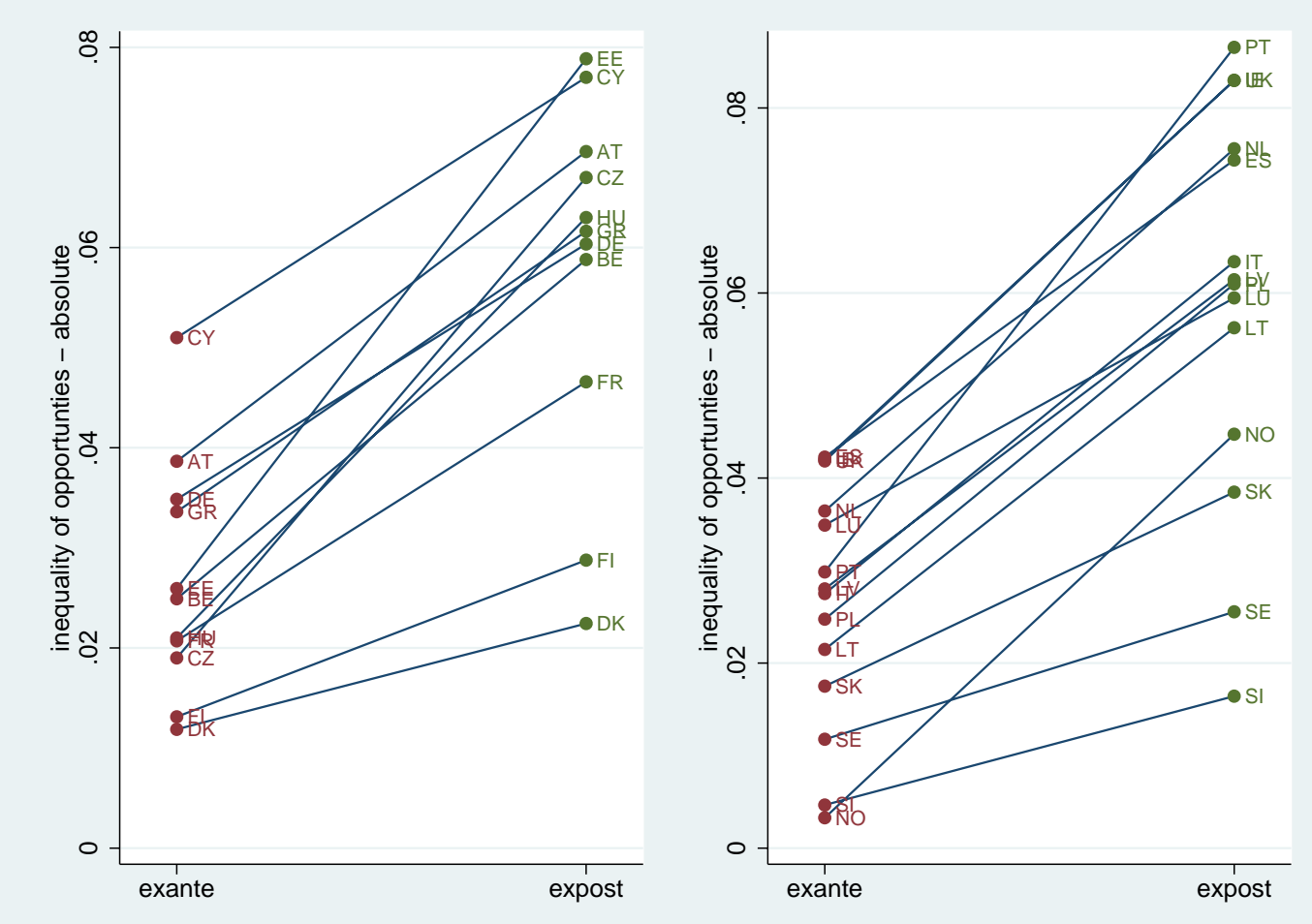

Sources: Authors's calculations 
Figure 4 - Income inequality and ex ante opportunity inequality - EUSILC 2005

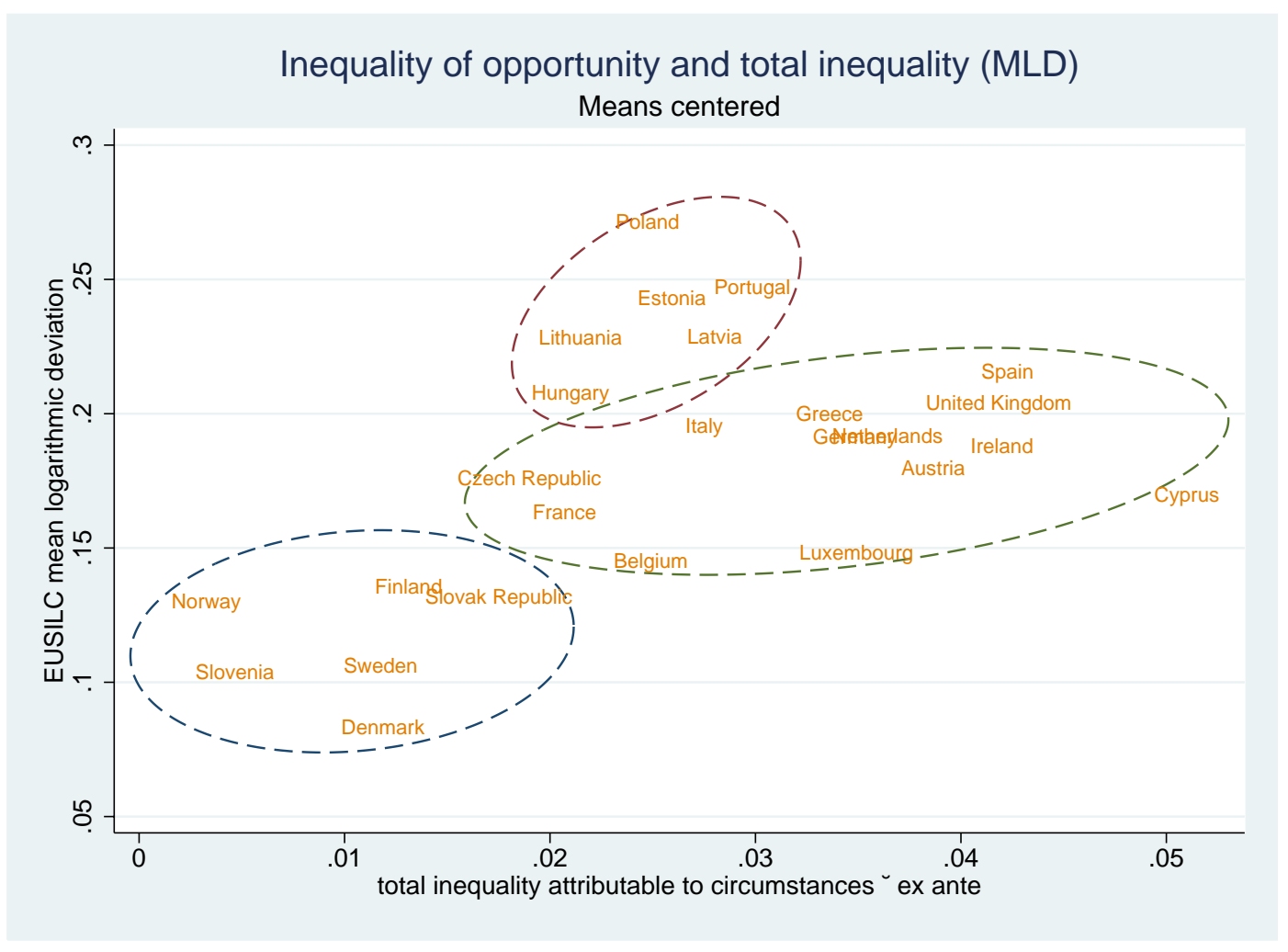

Sources: Authors's calculations 
Figure 5 - Income inequality and ex post opportunity inequality - EUSILC 2005

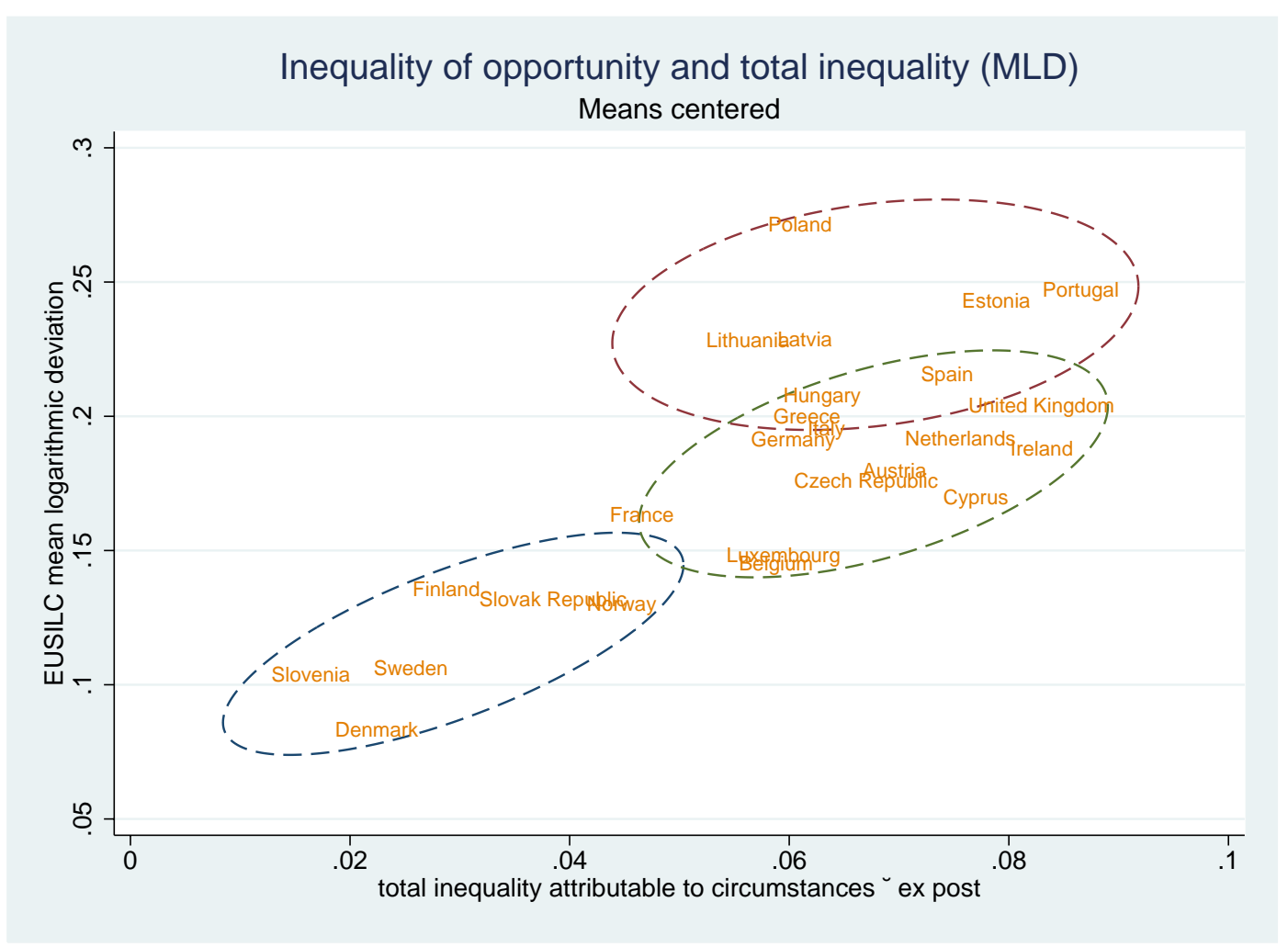

Sources: Authors's calculations 
Figure 6 - Cluster analysis based on inequality

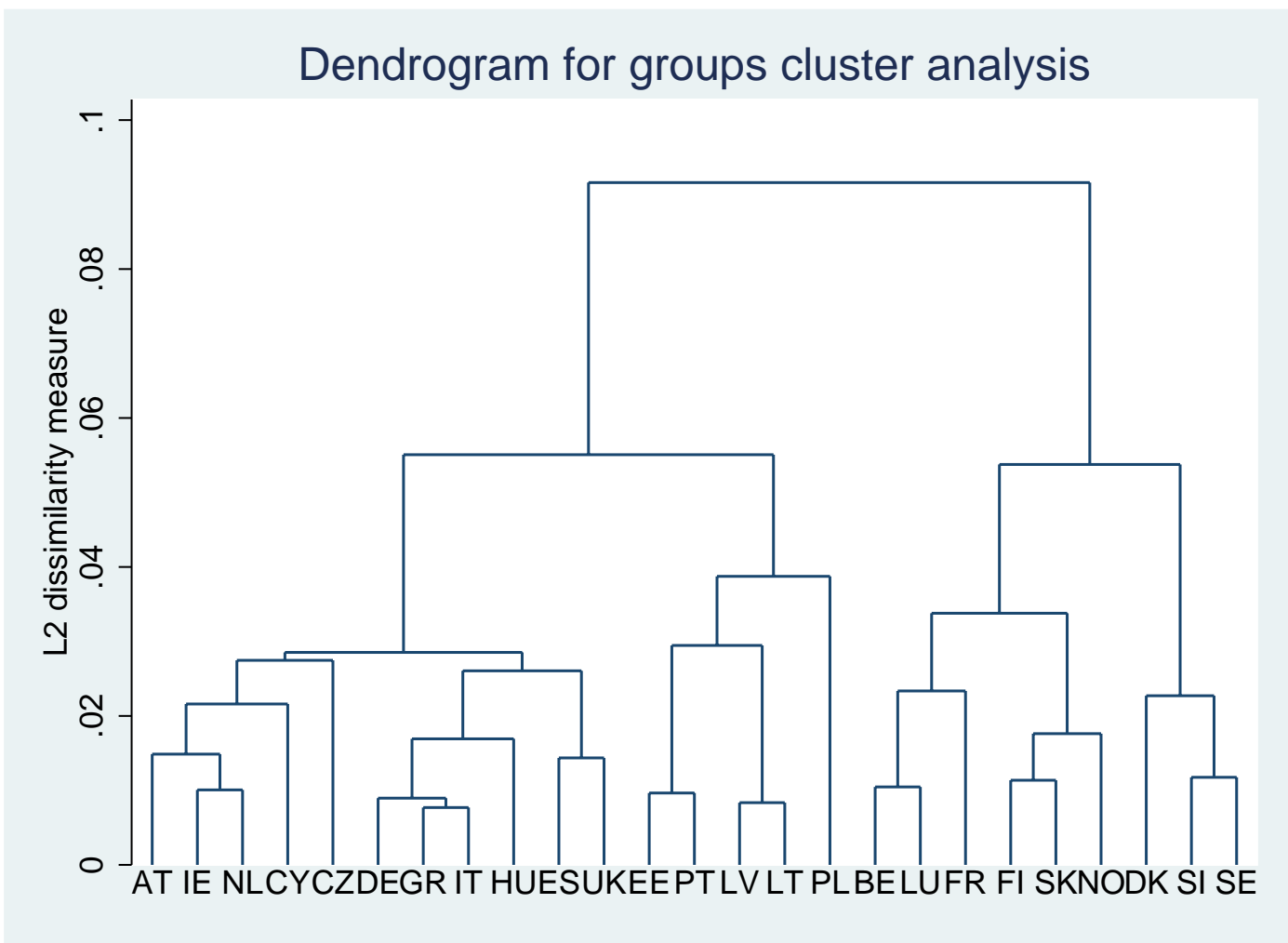

Sources: Authors's calculations 
Figure 7 - Opportunity inequality and schooling

Schooling and inequality of opportunities
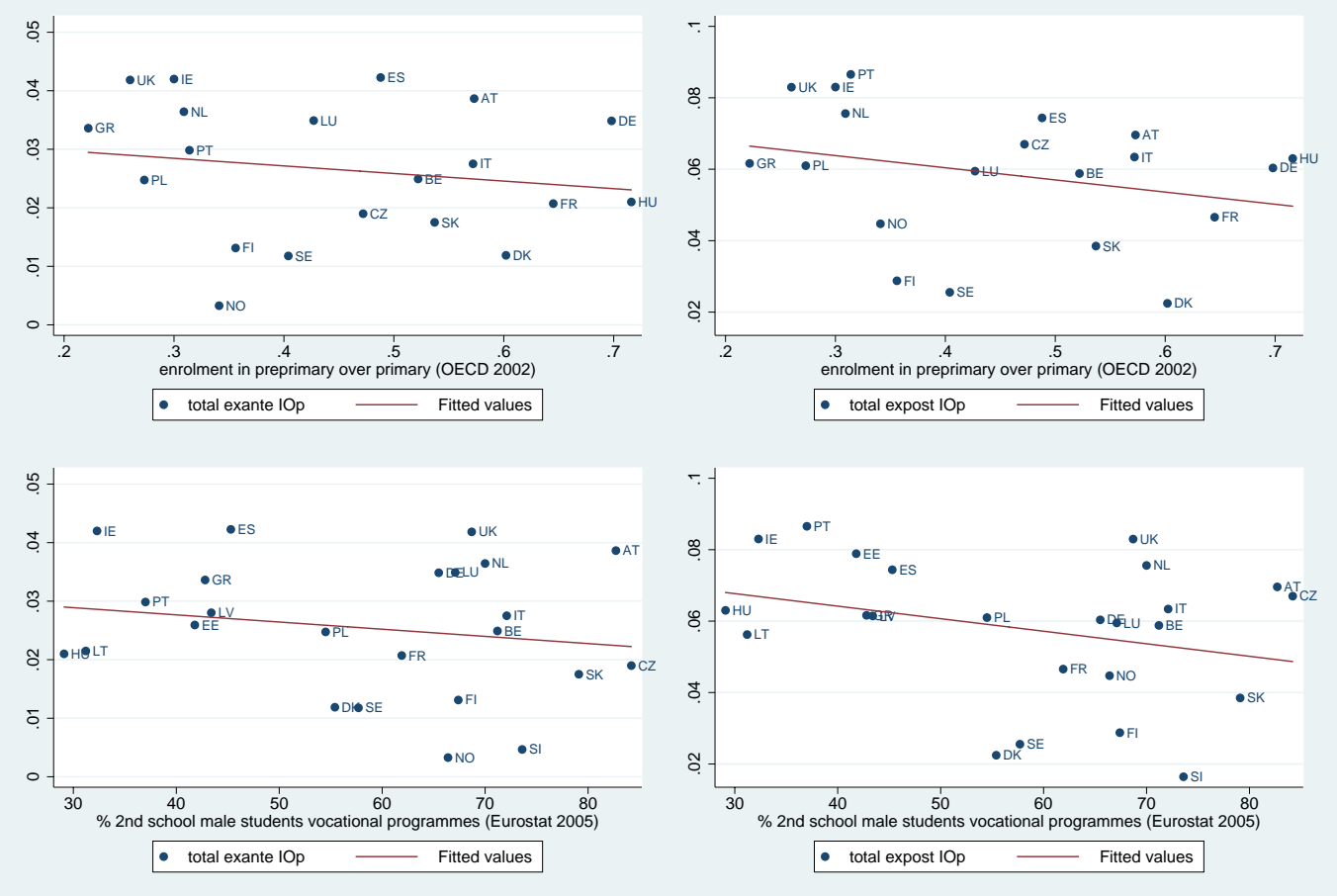

Sources: Authors's calculations 
Figure 8 - Opportunity inequality and educational resources

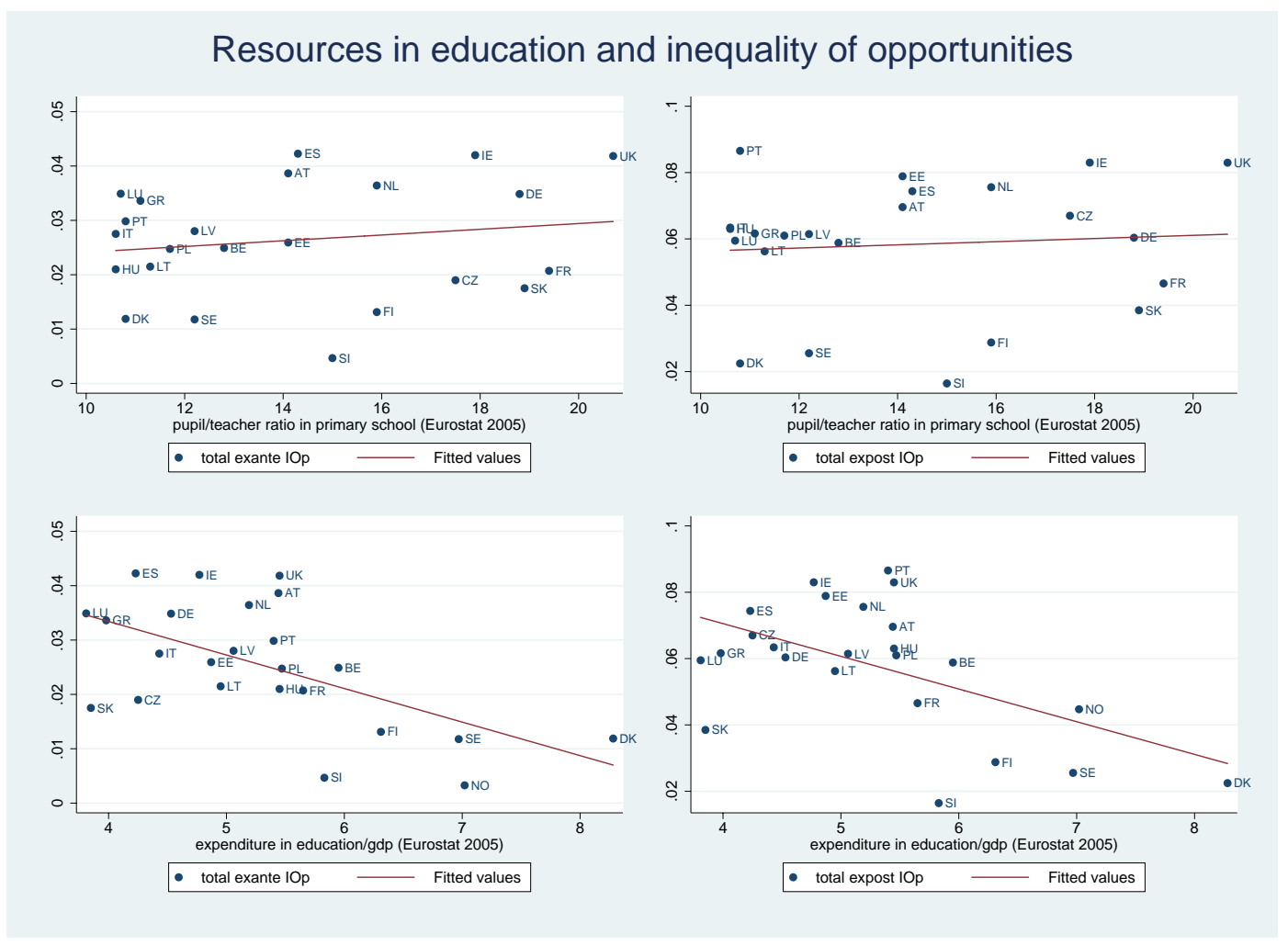

Sources: Authors's calculations 
Figure 9 - Opportunity inequality and labour market institutions

\section{Labour market institutions and inequality of opportunities}
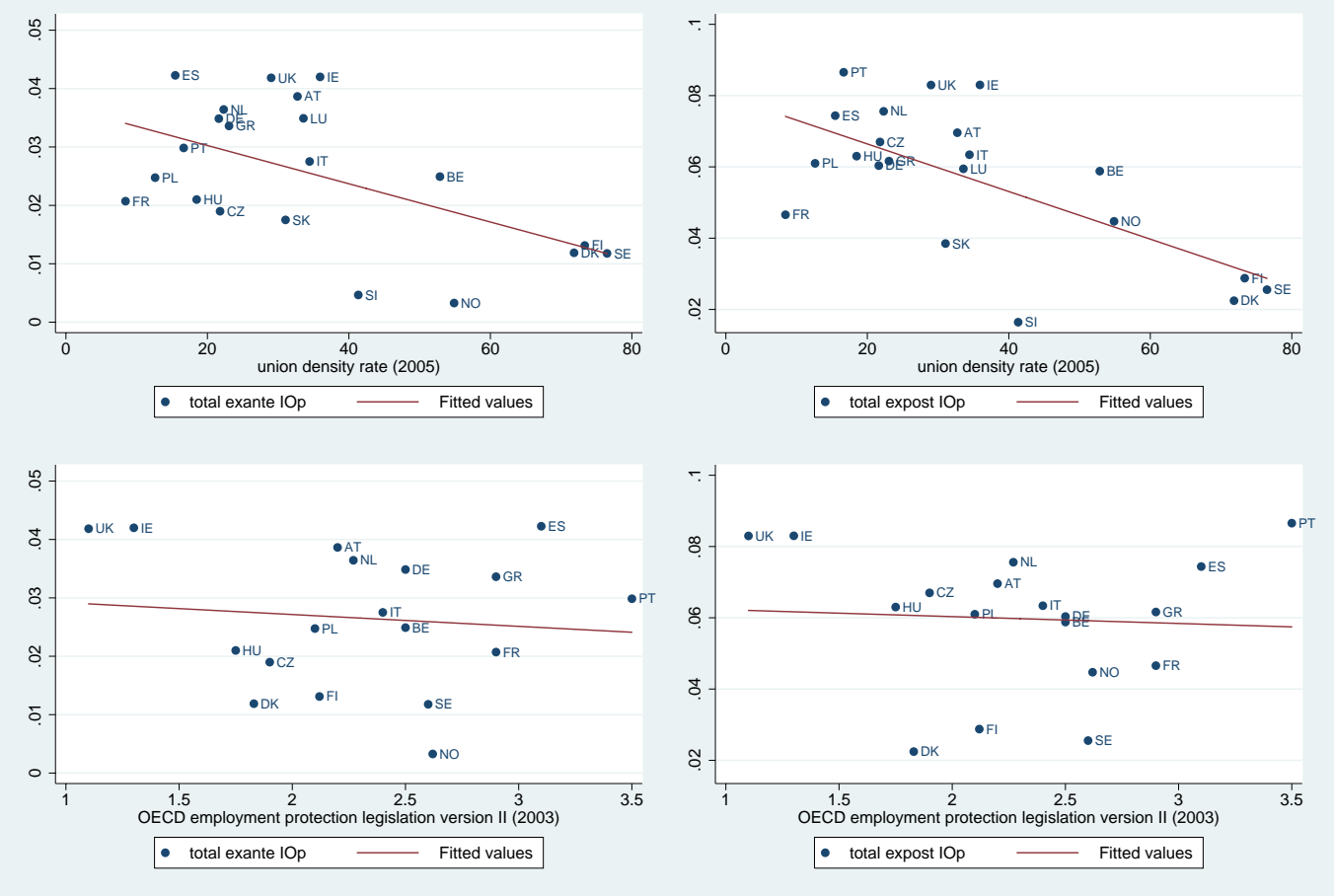

Sources: Authors's calculations 
Figure 10 - Opportunity inequality and the role of fiscal redistributione

Taxes and transfer and inequality of opportunities
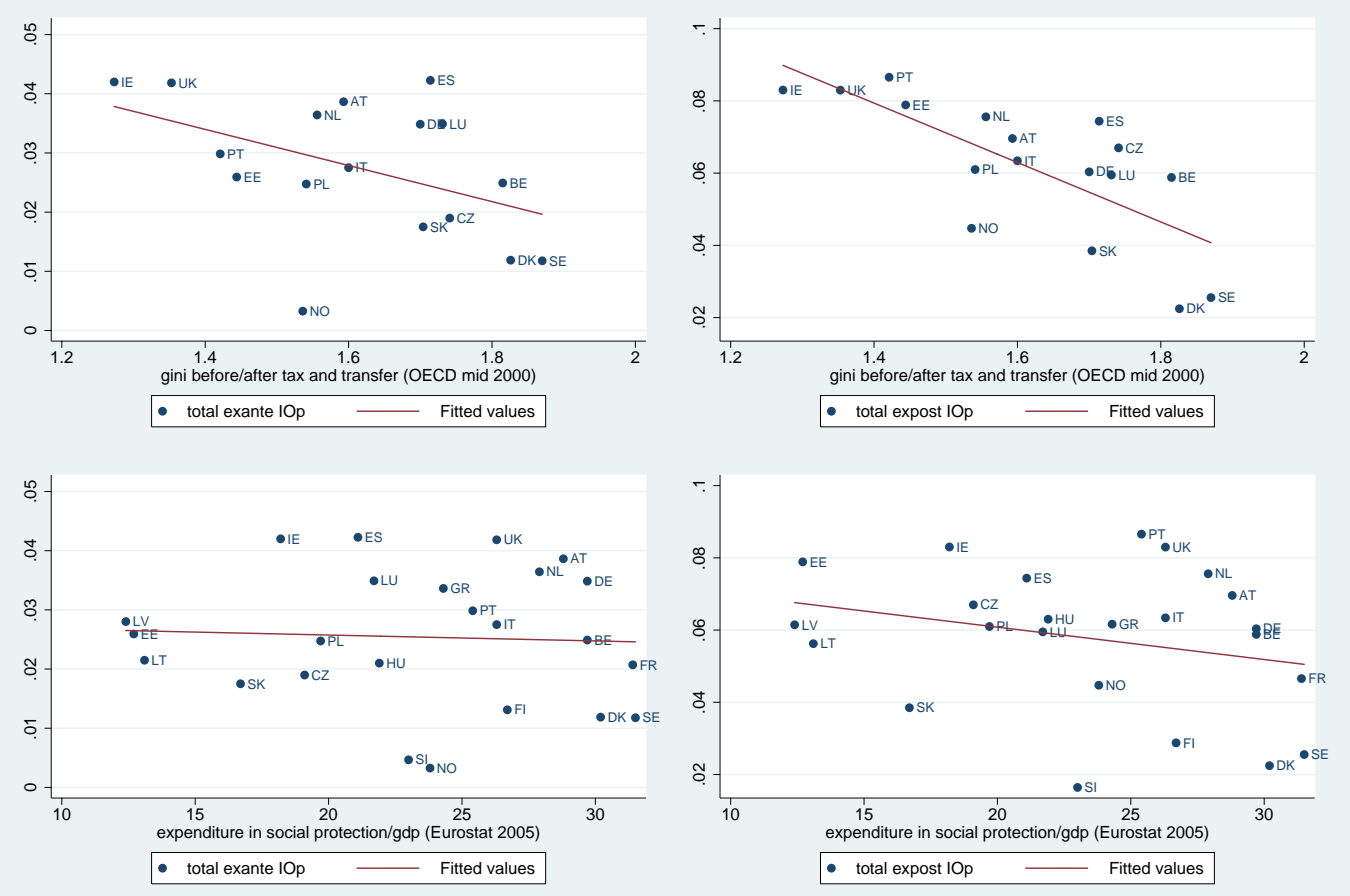

Sources: Authors's calculations 


\section{Appendix}

Table 5: Summary statistics on main individual variables

\begin{tabular}{|c|c|c|c|c|c|c|c|c|c|c|c|}
\hline country & mean $(\mathrm{x})$ & $\mathrm{sd}(\mathrm{x})$ & female & foreign & not densely & 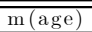 & $\overline{\text { sd(age) }}$ & education & & & $\overline{\bar{N}}$ \\
\hline & & & & & pop & & & 1 & 2 & 3 & \\
\hline $\mathrm{AT}$ & 18246.1 & 9001.4 & 0.51 & 0.11 & 0.27 & 43.3 & 8.0 & & 0.69 & 0.31 & 4,558 \\
\hline $\mathrm{BE}$ & 21607.1 & 12577.9 & 0.44 & 0.10 & 0.51 & 43.3 & 7.8 & 0.0052 & 0.51 & 0.49 & 2,995 \\
\hline $\mathrm{CY}$ & 13286.8 & 6507.7 & 0.45 & 0.13 & 0.58 & 43.4 & 8.3 & 0.0133 & 0.68 & 0.31 & 3,247 \\
\hline $\mathrm{CZ}$ & 4468.7 & 2299.0 & 0.47 & 0.03 & 0.31 & 43.9 & 8.8 & & 0.84 & 0.16 & 2,696 \\
\hline $\mathrm{DE}$ & 19603.9 & 10056.1 & 0.55 & 0.05 & 0.43 & 44.2 & 7.4 & & 0.48 & 0.52 & 7,421 \\
\hline D K & 19673.5 & 8300.3 & 0.50 & 0.04 & 0.32 & 44.3 & 8.5 & & 0.64 & 0.36 & 2,649 \\
\hline $\mathrm{EE}$ & 3808.8 & 2618.4 & 0.53 & 0.15 & 0.32 & 44.5 & 8.0 & & 0.56 & 0.44 & 2,801 \\
\hline ES & 14096.9 & 8102.7 & 0.41 & 0.06 & 0.49 & 42.7 & 8.3 & & 0.66 & 0.34 & 9,496 \\
\hline F I & 20982.7 & 10183.7 & 0.49 & 0.02 & 0.23 & 45.2 & 8.5 & & 0.59 & 0.41 & 3,798 \\
\hline $\mathrm{FR}$ & 19463.9 & 10138.8 & 0.48 & 0.11 & 0.44 & 43.5 & 8.2 & & 0.67 & 0.33 & 6,558 \\
\hline GR & 13771.9 & 8412.7 & 0.37 & 0.09 & 0.40 & 42.9 & 8.4 & & 0.70 & 0.30 & 3,812 \\
\hline $\mathrm{HU}$ & 3589.7 & 2151.5 & 0.51 & 0.02 & 0.32 & 42.8 & 8.5 & 0.0025 & 0.82 & 0.17 & 5,210 \\
\hline IE & 23497.2 & 12849.7 & 0.62 & 0.11 & 0.36 & 44.7 & 8.3 & & 0.57 & 0.43 & 3,446 \\
\hline IT & 18726.1 & 13843.6 & 0.42 & 0.05 & 0.35 & 43.0 & 8.1 & 0.0039 & 0.77 & 0.22 & 15,562 \\
\hline LT & 3081.6 & 2349.5 & 0.53 & 0.06 & 0.45 & 44.6 & 7.9 & & 0.37 & 0.63 & 3,170 \\
\hline $\mathrm{LU}$ & 30182.1 & 14510.6 & 0.44 & 0.50 & 0.46 & 41.4 & 8.1 & & 0.68 & 0.32 & 2,365 \\
\hline LV & 2939.6 & 2099.4 & 0.55 & 0.16 & 0.51 & 43.7 & 8.2 & 0.0010 & 0.62 & 0.38 & 2,104 \\
\hline NL & 18546.1 & 8591.0 & 0.51 & 0.05 & & 43.7 & 8.6 & & 0.57 & 0.43 & 3,637 \\
\hline $\mathrm{NO}$ & 20594.8 & 9874.7 & 0.48 & 0.06 & 0.51 & 43.7 & 8.7 & 0.0004 & 0.57 & 0.43 & 2,503 \\
\hline PL & 3690.3 & 2561.9 & 0.46 & 0.00 & 0.39 & 42.9 & 7.8 & 0.0026 & 0.75 & 0.25 & 9,377 \\
\hline $\mathrm{PT}$ & 9094.9 & 6268.2 & 0.45 & 0.02 & 0.35 & 43.2 & 8.4 & & 0.87 & 0.13 & 3,057 \\
\hline $\mathrm{SE}$ & 19452.9 & 8256.4 & 0.49 & 0.10 & 0.19 & 44.5 & 8.9 & & 0.57 & 0.43 & 2,435 \\
\hline SI & 9596.1 & 4124.1 & 0.48 & 0.11 & & 42.3 & 7.9 & & 0.77 & 0.23 & 2,623 \\
\hline SK & 3732.0 & 3183.4 & 0.49 & 0.02 & 0.28 & 43.8 & 8.0 & & 0.80 & 0.20 & 4,070 \\
\hline UK & 23861.1 & 13872.2 & 0.51 & 0.09 & 0.73 & 44.0 & 8.6 & & 0.55 & 0.45 & 5,421 \\
\hline
\end{tabular}

The columns of this table show the following statistics: 1 . average post tax individual income; 2 standard deviation of post tax individual incomes; 3 percentage of females; 4 . percentage of foreign born; 5 . percentage of individuals not living in a densely populated area; 6 . average age; 7 age standard deviation; 8 percentage of individuals with no education; 9 percentage of individuals with primary or secondary school degree; 10 percentage of individuals with higher degree. 11 number of observations. 
Table 6: Summary statistics on main parental variables

\begin{tabular}{lccccccc}
\hline \hline country & education & \multicolumn{7}{c}{ occupation } & & $\mathrm{N}$ \\
\hline & 1 & 2 & 3 & 1 & 2 & 3 & \\
AT & 0.00 & 0.93 & 0.07 & 0.09 & 0.31 & 0.59 & 4,558 \\
BE & 0.10 & 0.66 & 0.24 & 0.28 & 0.25 & 0.47 & 2,995 \\
CY & 0.26 & 0.66 & 0.08 & 0.08 & 0.30 & 0.62 & 3,247 \\
CZ & 0.00 & 0.89 & 0.11 & 0.13 & 0.17 & 0.70 & 2,696 \\
DE & 0.00 & 0.65 & 0.35 & 0.25 & 0.23 & 0.52 & 7,421 \\
DK & 0.00 & 0.78 & 0.22 & 0.22 & 0.30 & 0.48 & 2,649 \\
EE & 0.01 & 0.70 & 0.29 & 0.15 & 0.10 & 0.75 & 2,801 \\
ES & 0.20 & 0.69 & 0.11 & 0.12 & 0.28 & 0.60 & 9,496 \\
F & 0.03 & 0.80 & 0.17 & 0.17 & 0.32 & 0.52 & 3,798 \\
FR & 0.04 & 0.86 & 0.10 & 0.16 & 0.29 & 0.55 & 6,558 \\
GR & 0.24 & 0.67 & 0.09 & 0.14 & 0.51 & 0.35 & 3,812 \\
HU & 0.01 & 0.85 & 0.15 & 0.10 & 0.22 & 0.68 & 5,210 \\
IE & 0.02 & 0.84 & 0.15 & 0.38 & 0.14 & 0.48 & 3,446 \\
IT & 0.10 & 0.86 & 0.04 & 0.19 & 0.24 & 0.58 & 15,562 \\
LT & 0.04 & 0.69 & 0.28 & 0.12 & 0.11 & 0.77 & 3,170 \\
LU & 0.05 & 0.76 & 0.19 & 0.22 & 0.23 & 0.55 & 2,365 \\
LV & 0.01 & 0.75 & 0.23 & 0.13 & 0.10 & 0.77 & 2,104 \\
NL & 0.00 & 0.82 & 0.18 & 0.41 & 0.20 & 0.39 & 3,637 \\
NO & 0.00 & 0.56 & 0.44 & 0.25 & 0.30 & 0.45 & 2,503 \\
PL & 0.11 & 0.80 & 0.09 & 0.11 & 0.36 & 0.53 & 9,377 \\
PT & 0.34 & 0.63 & 0.03 & 0.08 & 0.31 & 0.61 & 3,057 \\
SE & 0.00 & 0.80 & 0.20 & & & & 2,435 \\
SI & 0.03 & 0.88 & 0.10 & 0.11 & 0.27 & 0.61 & 2,623 \\
SK & 0.00 & 0.89 & 0.11 & 0.14 & 0.14 & 0.72 & 4,070 \\
UK & 0.50 & 0.16 & 0.34 & & & & 5,421 \\
\hline
\end{tabular}

The columns of this table show the following statistics: 1. percentage of individuals who have at least one of the parents employed in the categories 8000 and 9000 of the ISCO88 classification; 2. percentage of individuals who have at least one of the parents employed in categories from 5000 to 7000 of the ISCO88 classification; 3. percentage of individuals who have at least one of the parents employed in categories 1000 to 4000 of the ISCO88 classification (see the text for further details); 4. percentage of individuals who have both parents with no education; 5 . percentage of individuals who have at least one of the parents with primary or secondary school degree; 6 . percentage of individuals who have at least one of the parents with post-secondary or higher degree; 7. number of observations available for the parental education variable.

Table 7: Tax rate in Cyprus

\begin{tabular}{lr}
\hline \hline Taxable income in euro & tax rate \\
\hline & \\
$15054-22580$ & 20 \\
$22581-30107$ & 25 \\
$30108-$ & 30 \\
\hline
\end{tabular}

Source: http://www.mof.gov.cy 
Table 8: Tax rate in Denmark

\begin{tabular}{lr}
\hline \hline Taxable income in euro & tax rate \\
\hline $0-3250$ & 0 \\
$32501-6500$ & 13.3 \\
$65001-9750$ & 19.2 \\
$97501-13000$ & 24.1 \\
$130001-16250$ & 27.6 \\
$162501-19500$ & 28.7 \\
$195001-26000$ & 30.4 \\
$260001-32500$ & 32.7 \\
$325001-39000$ & 34.5 \\
$390001-45500$ & 36.2 \\
$455001-52000$ & 38.9 \\
$520001-65000$ & 42.3 \\
$650001-97500$ & 48.4 \\
$975001-130000$ & 53 \\
130001 & 59.2 \\
\hline
\end{tabular}

Source: www.skm.dk.

Table 9: Tax rate in Finland

\begin{tabular}{lr}
\hline \hline Taxable income in euro & tax rate \\
\hline & \\
$12200-17000$ & 9 \\
$17001-20000$ & 14 \\
$20001-32800$ & 19.5 \\
$32801-58200$ & 25 \\
$58201-$ & 32.5 \\
\hline
\end{tabular}

Source: www.vero.fi.

Table 10: Tax rate in Hungary

\begin{tabular}{lr}
\hline \hline Taxable income in euro & tax rate \\
\hline $1-5960$ & 18 \\
$5961-$ & 38 \\
\hline
\end{tabular}

Source: www.worldwide-tax.com. 
Table 11: Tax rate in the Netherlands

\begin{tabular}{lr}
\hline \hline Taxable income in euro & tax rate \\
\hline $1-16265$ & 0 \\
$16266-29543$ & 7.95 \\
$29544-50652$ & 42 \\
$50653-$ & 52 \\
\hline
\end{tabular}

Source: OECD.

Table 12: Tax rate in Norway

\begin{tabular}{lr}
\hline \hline Taxable income in NOK & tax rate \\
\hline lower limit & tax rate \\
0 & 0.0 \\
$29600-43022$ & 25.0 \\
$43023-65999$ & 7.8 \\
$66000-102580$ & 35.8 \\
$102581-185160$ & 27.1 \\
$185161-380999$ & 35.8 \\
$381000-799999$ & 47.8 \\
800000 & 51.3 \\
\hline
\end{tabular}

Source: www.Taxnorway.no.

\section{References}

Alesina, A. and La Ferrara, E. 2005. Preferences for Redistribution in the Land of Opportunities. Journal of Public Economics, 89: 897-931.

Arneson R. 1989. Equality of Opportunity for Welfare. Philosophical Studies, 56: 77-93.

Björklund A., Jäntti M. and Roemer J.E. 2010. Equality of opportunity and the distribution of long-run income in Sweden. mMimeo.

Bourguignon, F, Ferreira F.H.G. and Menendez, M. 2003. Inequality of Outcomes and Inequality of Opportunities in Brazil. DELTA Working Papers 24.

Bourguignon, F, Ferreira F.H.G. and Walton, M. 2007. Equity, Efficiency and Inequality Traps: A research Agenda. Journal of Economic Inequality 5: 235-256.

Brunello, G. and Checchi, D. 2007. Does School Tracking Affect Equality of Opportunity? New International Evidence, Economic Policy, 52: 781-861.

Checchi, D. and Garcia Penalosa, C. 2008. Labour Market Institutions and Income Inequality, Economic Policy, 23:601-649.

Checchi D. and Peragine V. 2009. Inequality of opportunity in Italy, Journal of Economic Inequality (forthcoming)

Cohen G. A. 1989 On the currency of egalitarian justice. Ethics, 99: 906-944. 
Cowell, F. A. and Victoria-Feser, M.P. 1996a. Poverty measurement with contaminated data: A robust approach. European Economic Review, 40:1761-1771.

Cowell, F. A. and Victoria-Feser, M.P. 1996b. Robustness properties of inequality measures. Econometrica, 64:77-101.

Cowell, F. A. and Victoria-Feser, M.P. 2002. Welfare rankings in the presence of contaminated data. Econometrica, 70:1221-33.

Cunha, F. and J.Heckman. 2007. The Technology of Skill Formation. American Economic Review, 97:31-47.

Dardanoni V., Fields G., Roemer J. E. and Sanchez-Puerta M. L. 2006. How demanding should equality of opportunity be and how much we have achieved?, in Morgan S. L., Grusky D. B. and Fields G. Mobility and Inequality, Stanford University Press;

Dworkin R. 1981a,b What is equality? Part1: Equality of welfare. Part2: Equality of resources. Philos Public Affairs 10, 185- 246, 283-345.

Ferreira F. H. G., Gignoux J. 2008. The measurement of inequality of opportunity: Theory and an application to Latin America. The World Bank Policy Research working paper n.4659;

Fleurbaey M. 1995. Three solutions for the compensation problem, Journal of Economic Theory, 65: 505- 521.

Fleurbaey M. 2008. Fairness, responsibility and welfare. Oxford University Press.

Fleurbaey M. and Peragine V. 2009 Ex ante versus ex post equality of opportunity ECINEQ working paper n.141/2009

Foster J.E. and Shneyerov A.A. 2000 Path Independent Inequality Measures. J. Econ. Theory, 91, 199-222.

Hall, P. and D. Soskice. 2001. Varieties of capitalism: the institutional foundations of comparative advantage. Oxford University Press

Hanushek, E. and L.Wößmann. 2006. Does Educational Tracking Affect Performance and Inequality? Differences-In-Differences Evidence Across Countries. Economic Journal, 116: C63-C76.

Heckman, J. J., Krueger, A. B., \& Friedman, B. M. 2002. Inequality in America: what role for human capital policies? Cambridge, Mass.: MIT Press.

Kranich, L. 1996. Equitable Opportunities: An Axiomatic Approach, Journal of Economic Theory, 71: 131-147.

Lefranc A., Pistolesi N. and Trannoy A. 2008. Inequality of opportunity vs inequality of outcomes: are western societies all alike? Review of Income and Wealth, 54:513-546.

Luongo P. and V. Peragine. 2009. The implication of partial observability of circumstances on the measurement of EOp. Mimeo.

Moreno-Ternero J. 2007 On the design of equal-opportunity policies, Investigaciones económicas, 31: 351-374.

OECD 2004. Economic Outlook. Paris. 
OECD 2009. Growing Unequal? Income distribution and poverty in OECD countries. Paris.

Peragine V. 2002. Opportunity egalitarianism and income inequality: a rank-dependent approach. Mathematical Social Sciences, 44:45-64.

Peragine V. 2004a. Measuring and implementing equality of opportunity for income. Social Choice and Welfare, 22:187-210.

Peragine V. 2004b Ranking income distributions according to equality of opportunity, in Journal of Economic Inequality, 2: 11-30.

Peragine V., Serlenga L. 2008. Higher education and equality of opportunity in Italy. In J. Bishop and B. Zheng (eds.) Research in Economic Inequality, 16:1-31.

Paes de Barros R., Ferreira F., Molinas Vega J.R., Saavedra Chanduvi J. 2009. Measuring inequality of opportunities in Latin America and the Caribbean. Palgrave MacMillan and The World Bank.

Pistolesi N. 2009. Inequality of opportunity in the land of opportunities, 1968-201, Journal of Economic Inequality, 7:411-433.

Roemer J.E. 1993 A pragmatic theory of responsibility for the egalitarian planner. Philosophy and Public Affairs 22, 146-166.

Roemer, J.E. 1998. Equality of Opportunity. Harvard University Press, Cambridge, M.A.

Van de Gaer D. 1993, Equality of opportunity and investment in human capital. Ph.D. Dissertation, Catholic University of Leuven.

Van Kerm, P. Extreme incomes and the estimation of poverty and inequality indicators from EU-SILC, IRISS Working Paper Series, 2007-01

Villar, A. 2006. On the welfare evaluation of income and opportunity. Contributions to Theoretical Economics, Berkeley Electronic Press, 5: 11291129.

Visser J. and D.Checchi. 2009. Inequality and the labour market: Unions. In W.Salverda, B.Nolan and T.Smeeding, (eds) Oxford Handbook of Economic Inequality, Oxford University Press

World Bank. 2006. World Development Report 2006: Equity and Development. Washington, DC: The World Bank and Oxford University Press. 